Fecha de recepción: noviembre 2019 Fecha de aceptación: diciembre 2019 Versión final: marzo 2020

\section{La nueva enseñanza del Diseño Gráfico en la Pontificia Universidad Católica del Ecuador}

Xavier Fernando Jiménez Álvaro ${ }^{(1)}$, Anabel Soraya Quelal Moncayo ${ }^{(2)}$, y Guillermo Sánchez Borrero ${ }^{(3)}$

Resumen: Con la aprobación en el Ecuador de la nueva Ley Orgánica de Educación Superior (LOES) en el año 2010 y sus respectivos Reglamento de Régimen Académico (RRA) 2012 y Reglamento de Presentación y Aprobación de Carreras y Programas de las Instituciones de Educación Superior (RPACP) en 2014 y emitido por el Consejo de Educación Superior CES se dio inicio al rediseño de programas de estudio de grado y postgrado en el país. En este contexto se presenta la nueva propuesta de la carrera de Diseño Gráfico, considerando la pertinencia del currículo en el cual se integran los aprendizajes de los conocimientos teóricos de la disciplina del Diseño Gráfico, con las destrezas profesionales para que los estudiantes sean capaces de aportar soluciones de diseño desde una visión estratégica y alto valor simbólico, orientadas a las demandas del sector público, de la pequeña y mediana empresa, de las organizaciones sociales y comunidades. Una propuesta de educación integral basada en el desarrollo de su proyecto de vida personal y profesional a partir del fortalecimiento de la vocación, la meta cognición, la autorregulación y la responsabilidad personal, social y ambiental, en un marco de observancia de los valores éticos, humanos y cristianos característicos de la pedagogía Ignaciana ${ }^{1}$ y el buen vivir.

Esta propuesta enmarcada en la misión y visión Institucional de la PUCE se concreta en el currículo y su plan de estudio que refleja el fortalecimiento de la enseñanza del diseño basado en la resolución de problemas concretos, con requerimientos y usuarios reales. Toma como eje el proyecto de Diseño y en sus tres etapas correspondientes al método proyectual. Relaciona además las asignaturas de forma horizontal y vertical de manera unificada confluyendo, de esta manera, en el desarrollo de proyectos cortos y largos que evidencien las competencias que deben tener los diseñadores a su egreso.

Palabras clave: Diseño gráfico - enseñanza - currículo - diseño curricular.

[Resúmenes en inglés y portugués en las páginas 59-60]

(1) Adscrito a la Pontificia Universidad Católica del Ecuador, en la Carrera de Diseño Gráfico de la Facultad de Arquitectura, Diseño y Artes. Diseñador por la Pontificia Universidad Católica del Ecuador (PUCE), Certificación en Emprendimiento y Liderazgo por la Universidad de las Américas Ecuador (UDLA) y la Cámara de Comercio de Quito, Máster en Diseño por la Universidad de Palermo (UP) (Argentina). Candidato a Doctor en Diseño por la Universidad de Palermo (UP) (Argentina). Docente a tiempo completo de la Ca- 
rrera de Diseño Gráfico de la PUCE y responsable del Rediseño e implementación Curricular. Investigación en diseño de identidad gráfica, metodología y enseñanza del Diseño.

(2) Adscrita a la Pontificia Universidad Católica del Ecuador, en la Carrera de Diseño Gráfico de la Facultad de Arquitectura, Diseño y Artes. Diseñadora gráfica por la Pontificia Universidad Católica del Ecuador (PUCE), Máster en Dirección de Comunicación Corporativa (DirCom) por la Universidad de las Américas (UDLA). Candidata a Doctora en Diseño por la Universidad de Palermo (UP) (Argentina). Docente a tiempo completo de la Carrera de Diseño Gráfico de la PUCE. Investigación en la enseñanza del diseño gráfico.

${ }^{(3)}$ Adscrito a la Pontificia Universidad Católica del Ecuador, en la Carrera de Diseño Gráfico de la Facultad de Arquitectura, Diseño y Artes. Diseñador por la Pontificia Universidad Católica del Ecuador (PUCE), Diplomado en Comunicación Corporativa por la Universidad Técnica Particular de Loja (UTPL) y Máster en Dirección de Comunicación Corporativa (DirCom) por la Universidad de las Américas (UDLA). Candidato a Doctor en Diseño por la Universidad de Palermo (UP) (Argentina). Docente a tiempo completo de la Carrera de Diseño de la PUCE y encargado de la Unidad de Titulación. Investigación en diseño para educación, el diseño gráfico en la pedagogía y la enseñanza del diseño gráfico.

\section{1) Antecedentes:}

Desde que asume la presidencia del Ecuador el Economista Rafael Correa Delgado en enero del año 2007 promueve como uno de los ejes de trabajo la transformación del Sistema de Educación Superior del país con la finalidad de "recuperar el rol director, regulador y supervisor del Estado sobre las instituciones de educación superior, claramente venido a menos durante décadas de gobiernos que, crecientemente, lo abandonaron delegándolo a las "fuerzas del mercado".(CONEA, 2009, p. 1)

Para esto, el 22 de julio del 2008 la Asamblea Nacional Constituyente emite el Mandato Constituyente No. 14. Este establece la obligación del Consejo Nacional de Evaluación y Acreditación (CONEA) de elaborar un informe técnico sobre el nivel de desempeño institucional de los establecimientos de educación superior, a fin de garantizar su calidad, propiciando su depuración y mejoramiento.

A partir de este proceso se propone y aprueba en el 2010 la Ley Orgánica de Educación Superior (LOES) como instrumento matriz y organizador del sistema de educación superior del país. De esta ley se desprenden el Reglamento de Régimen académico, reglamento de nomenclatura y armonización de títulos, reglamento de carrera y escalafón de profesor e investigador del sistema de educación superior, reglamento de presentación y aprobación de carreras y programas de las instituciones de Educación Superior, entre otros. Con los reglamentos dispuestos y aprobados se inicia el proceso de rediseño de la oferta de las carreras del Sistema de Educación Superior del País. 
En este contexto La Pontificia Universidad Católica del Ecuador, su Facultad de Arquitectura, Diseño y Artes y específicamente la Carrera de Diseño Gráfico en su sede matriz ubicada en la capital Quito y sus sedes en las ciudades de Esmeraldas, Ibarra y Santo Domingo presentan el año 2017 un currículo de 7200 horas, 9 períodos académicos de duración, cuya formación responde al tercer nivel de educación superior y que oferta el título de Licenciatura en Diseño Gráfico. (tabla 1) Este currículo inicia su implementación en el primer semestre del año 2018, siendo uno de los pioneros en el país al ser aprobado en primera instancia por el Sistema estatal.

En el año 2019 se expide un nuevo reglamento de régimen académico en el Ecuador lo que permite a las Universidades acogerse a un plan de ajuste de rediseño curricular y la transición a un plan de estudios reducido. La PUCE se acoge a esta disposición y propone el nuevo currículo (tabla 2), para lo cual declara el cumplimiento de lo establecido por el reglamento que consistió en:

- No modificar el objeto de estudio, objetivos de aprendizaje, perfil de egreso, modalidad de estudios, denominación de la carrera o programa o denominación de la titulación.

- El proceso de transición garantiza:

a) Los derechos de los estudiantes a no extender la duración de sus estudios ni incurrir en costos adicionales;

b) Abarcará todas las mallas curriculares anteriores de las carreras y programas rediseñados;

c) Proceder de forma planificada, transparente y sistemática, cuidando el rigor académico y la preservación de la calidad.

d) Posibilitar la transición del anterior al nuevo Reglamento de Régimen Académico para que la Pontificia Universidad Católica del Ecuador, en el marco de la autonomía responsable, aplique mecanismos o procedimientos transparentes y flexibles de convalidación y análisis de contenidos que reconozcan las horas y/o créditos cursados por los estudiantes en las mallas curriculares anteriores. (PUCE, 2019a, p. 32)

El currículo final propuesto que empieza con la transición e implementación en el segundo semestre del 2019 tiene 5760 horas y 8 períodos académicos de duración. Este currículo recoge el proceso de reflexión y propuesta realizado desde el año 2015 con todo el equipo de docentes de la Carrera en sus cuatro sedes, ha sido coordinado y elaborado por los docentes que escribimos este artículo y también ha sido aprobado por todas las instancias de facultad, universidad y dependencias estatales.

A continuación, se detalla la estructura del currículo propuesto. 


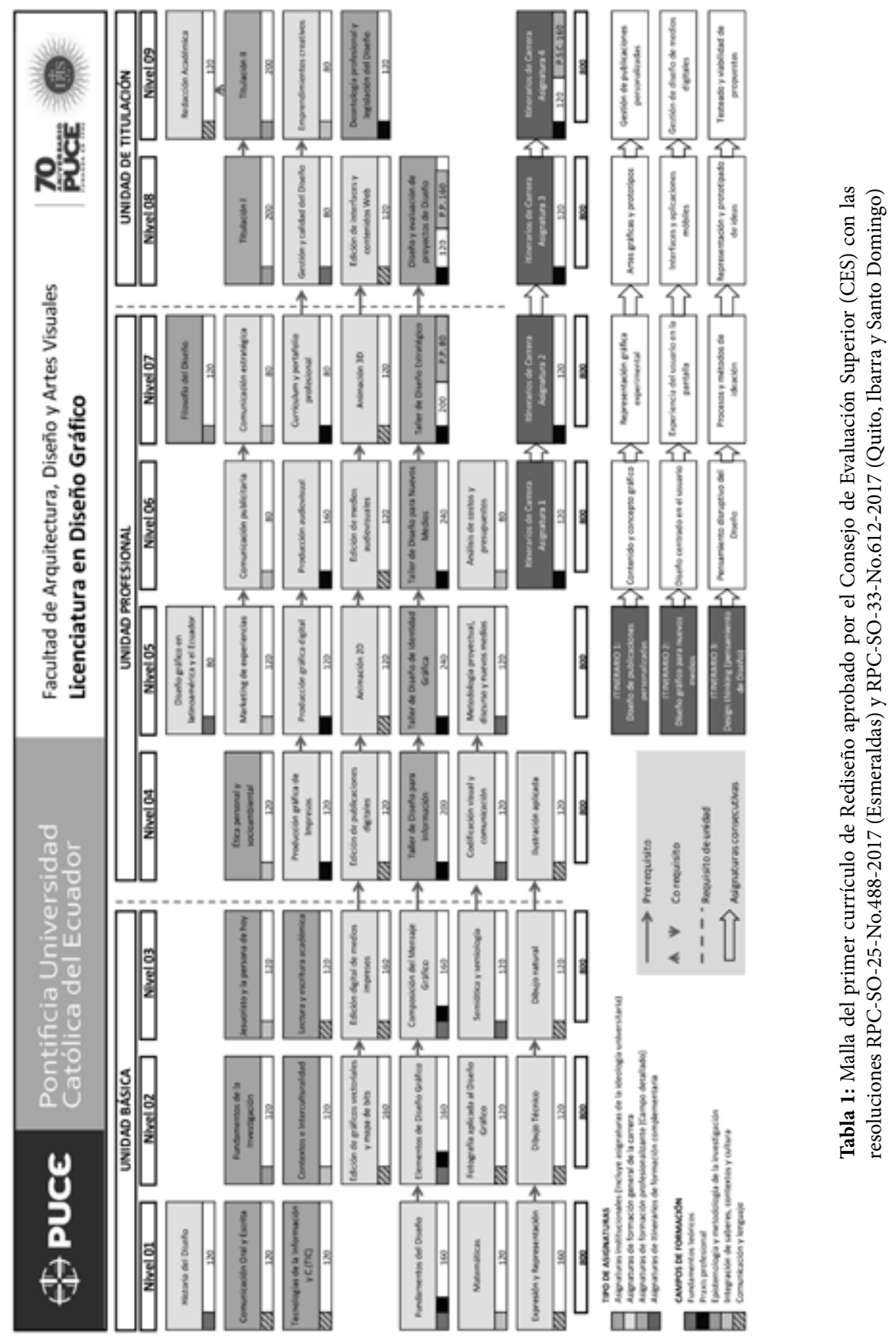




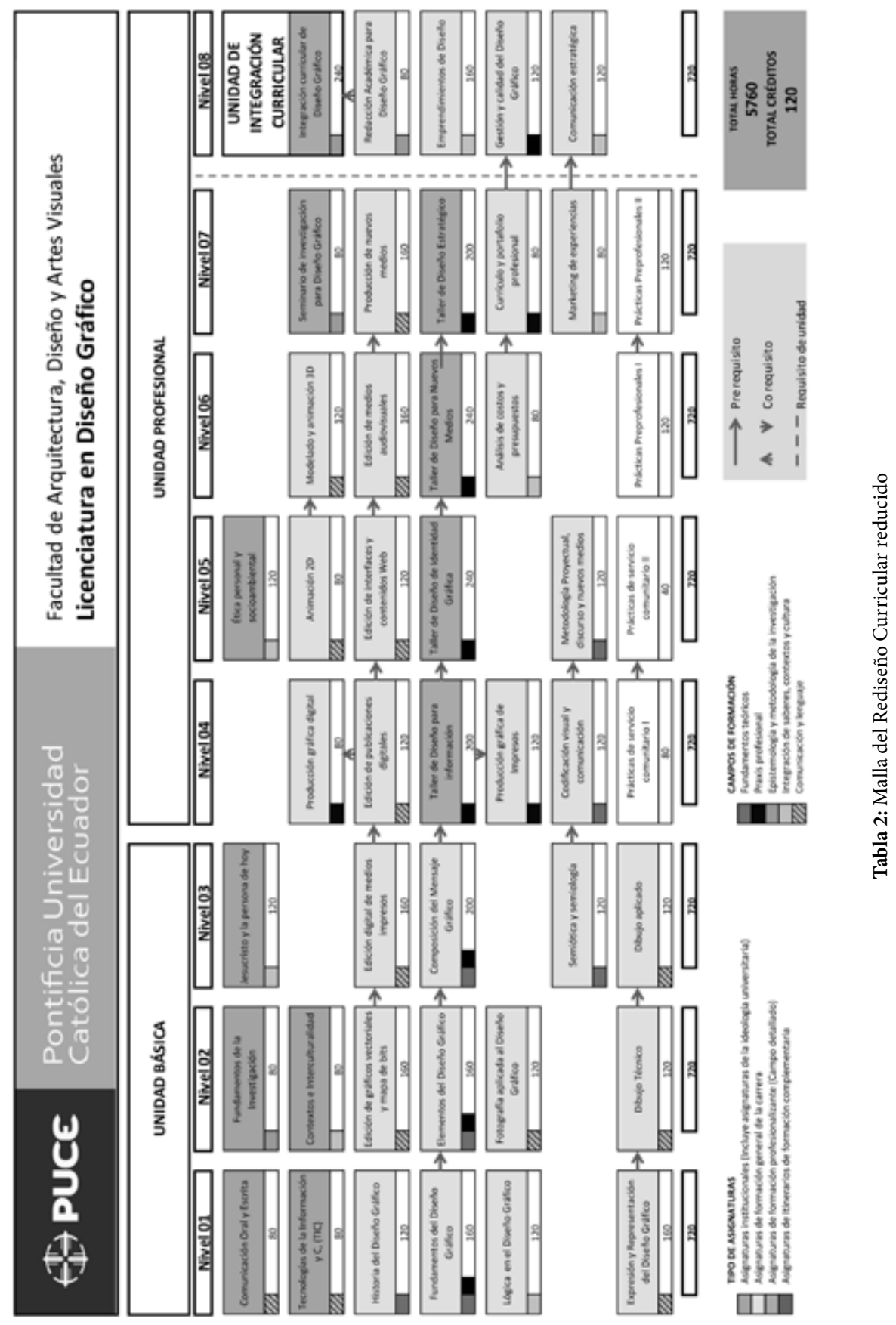




\section{2) Datos generales del proyecto de rediseño curricular}

Como se indicó, este rediseño curricular recoge la estructura y planteamiento del primer proyecto de rediseño presentado y aprobado en el año 2017 pero responde a la transición curricular propuesta por el estado para una oferta curricular reducida y posible solo para las universidades evaluadas y mejor categorizadas en el proceso de evaluación realizado por el estado. Esta propuesta propone un programa de estudios de 5760 horas y en 8 períodos académicos de 720 horas cada uno y un total de 45 asignaturas. Esta estructura macro responde a lo planteado en el Artículo 18 del Reglamento de Régimen Académico. (CES, 2019, p. 10)

Esta oferta no tiene períodos académicos extraordinarios, no propone itinerarios de formación y considera una demanda de ingreso de 25 estudiantes cuya proyección de matrícula al finalizar el octavo período sería de 119 como se indica en la tabla 3. En las ciudades de provincia Esmeraldas e Ibarra se considera que el número de estudiantes de ingreso sería de 20. Estos datos se obtuvieron en base al análisis histórico de los últimos 5 años de ingreso de estudiantes a la Carrera y a la proyección de crecimiento con la nueva oferta. En el rediseño del 2017 en la sede matriz se ofertó 2 paralelos de 25 alumnos, pero no se consiguió cumplir esta proyección en los 3 semestres de apertura primero y segundo 2018 y primero 2019. De esta manera se hizo este ajuste a 1 solo paralelo de 25 .

\begin{tabular}{|c|c|}
\hline Semestre & $\mathrm{N}^{\circ}$ de estudiantes por semestre \\
\hline 1 & 25 \\
\hline 2 & 46 \\
\hline 3 & 64 \\
\hline 4 & 79 \\
\hline 5 & 92 \\
\hline 6 & 102 \\
\hline 7 & 111 \\
\hline
\end{tabular}

Tabla 3. Proyección de matrícula. Fuente: (PUCE, 2019b, p. 6) 
Las modalidades de titulación son: trabajo de integración curricular y examen de carácter complexivo. La jornada de trabajo propuesta es diurna y la carrera se abrirá cada semestre. Con relación a las políticas de permanencia y promoción del cuerpo docente, la PUCE garantiza el incorporar docentes con el más alto nivel académico, en relación de dependencia y por medio de un concurso público de merecimientos y oposición dispuesto en su estatuto y de acuerdo con las disposiciones legales del estado.

El objetivo general de la carrera propone:

Formar profesionales en Diseño Gráfico que desde la visión Ignaciana de ser más para servir mejor integren la excelencia humana con las competencias profesionales para dar soluciones a problemas de comunicación visual presentes en la sociedad, a través de proyectos interdisciplinarios y sostenibles abordados desde enfoques teóricos, prácticos e investigativos que aporten a la cultura e identidad visual y al desarrollo social con conciencia ecológica. (PUCE, 2019b, p. 18)

Los objetivos específicos se proponen en cuatro áreas específicas:

\section{a) Al Conocimiento:}

Definir las características históricas y socioculturales que condicionan la construcción de los lenguajes visuales propios del Diseño Gráfico y su expresión en los entornos social, natural y tecnológico.

Identificar los elementos y las relaciones entre los distintos actores del proceso de comunicación y específicamente del Diseño gráfico mediante un abordaje teórico conceptual, metodológico y de investigación adecuado, que permita determinar las características y condiciones del proyecto de Diseño y el conocimiento y dominio de sus elementos de configuración práctica.

\section{b) A la Pertinencia:}

Ofrecer un currículo que aporte soluciones de Diseño, desde una visión estratégica y alto valor simbólico, orientadas a las demandas del sector público, de la pequeña y mediana empresa, de las organizaciones sociales y comunidades. Integrar los avances científicos tecnológicos, así como los saberes ancestrales de forma trans, multi e inter disciplinariamente en propuestas de Diseño efectivas que aporten al desarrollo social, económico y cultural del país.

\section{c) A los Aprendizajes:}

Integrar los conocimientos teóricos de la disciplina del Diseño Gráfico, con las competencias profesionales para el desarrollo de soluciones viables en los diferentes entornos sociales, económicos y laborales, que prioricen la reflexión teórica, metodológica y de investigación, pero logren implementar efectivamente las soluciones propuestas con un alto dominio de herramientas técnicas y conocimiento tecnológico actual. 
Fomentar una educación integral basada en el desarrollo de proyecto de vida personal y profesional a partir del fortalecimiento de la vocación, la meta cognición, la autorregulación y la responsabilidad personal, social y ambiental, en un marco de observancia de los valores éticos, humanos y cristianos característicos de la pedagogía Ignaciana y el buen vivir.

\section{d) A la ciudadanía Integral:}

Participar en comunidades de aprendizaje y de práctica profesional del Diseño Gráfico que amplíen perspectivas, visiones y horizontes de futuro de los contextos y actores sociales, en el marco del ejercicio de deberes y derechos profesionales, del conocimiento como del bien público y social.

Estructurar una oferta académica de Diseño Gráfico que incorpore diversas perspectivas culturales de identidad, educación en valores, derechos y participación ciudadana, tendientes a fortalecer una visión inclusiva, sostenible, de género y de respeto a la diversidad con conciencia crítica y liderazgo. (PUCE, 2019b, pp. 19-20)

Para el ingreso a la carrera los estudiantes postulantes deben cumplir los requisitos formales establecidos por la Universidad y principalmente haber obtenido un título como graduados del bachillerato y cumplir con el perfil de salida del Bachillerato General Unificado del Ecuador en donde se hace énfasis en tres aspectos:

- Comunicarse efectivamente

- Razonar numéricamente

- Representar técnicamente elementos bidimensionales.

Este perfil si bien se evidencia en los documentos formales establecidos por el estado, en los cuatro semestres en que se ha implementado el currículo, es evidente la deficiencia en la formación con la que llegan los estudiantes desde el bachillerato. Esto ha exigido que los docentes pongan mayor atención en fortalecer las competencias básicas y la Universidad a propuesto un grupo de asignaturas comunes a todos los currículos para consolidar esta formación básica. Estos aspectos se detallarán más adelante.

\section{3) Pertinencia}

\section{3a) Problemas y objetivos de planificación}

Para poder proponer este currículo se tuvo que justificar su pertinencia frente a las necesidades y desafíos del contexto local, regional y mundial. Para esto se determinó en primera instancia los problemas y necesidades de los contextos y los objetivos del Plan Nacional de Desarrollo del Ecuador que abordará la profesión. Los problemas identificados y que se proponen enfrentar son: 
P1. Deficiencia en el diseño de piezas editoriales y material didáctico; señalización y familiarización con interfaces para medios digitales, impresos, tridimensionales o electrónicos.

P2. Deficiencia en la calidad de propuestas persuasivas visuales en el campo de la publicidad, propaganda, comunicaciones de interés social y revestimiento de envases, para la promoción y comercialización de productos y servicios.

P3. Reducida e insuficiente calidad de material educativo para apoyar el desarrollo e inclusión tanto de individuos como de comunidades que aporten a la valoración de la cultura propia.

P4. Bajo nivel de soluciones creativas, innovadoras de diseño de mensajes visuales que posibiliten el logro de eficiencia, seguridad, bajo nivel de desgaste físico y optimización de recursos.

P5. Subvaloración de la identidad e imagen organizacional como estrategia de reconocimiento, apropiación y competitividad.

P6. Escaso nivel de propuestas comunicacionales visuales que propicien y concienticen la conservación del patrimonio natural y cultural. (PUCE, 2019b, p. 21)

Si bien la disciplina del Diseño Gráfico es transversal y puede aportar a todas las áreas de desarrollo del país, se consideró atender prioritariamente a los siguientes objetivos propuestos en el Plan Nacional de Desarrollo 2017-2021 “Toda una vida” del gobierno del presidente Lenin Moreno (CNP, 2017) y en relación con los problemas definidos:

Objetivo 1: Garantizar una vida digna con iguales oportunidades para todas las personas

1.4 Garantizar el desarrollo infantil integral para estimular las capacidades de los niños y niñas, considerando los contextos territoriales, la interculturalidad, el género y las discapacidades.

1.15 Promover el uso y el disfrute de un hábitat seguro, que permita el acceso equitativo a los espacios públicos con enfoque inclusivo.

Objetivo 2: Afirmar la interculturalidad y plurinacionalidad, revalorizando las identidades diversas

2.3 Promover el rescate, reconocimiento y protección del patrimonio cultural tangible e intangible, saberes ancestrales, cosmovisiones y dinámicas culturales.

2.5 Garantizar la preservación de las lenguas tradicionales, el multilingüismo y el sostenimiento de sistemas de educación intercultural y conocimiento de las diversidades.

2.7 Promover la valoración e inclusión de los conocimientos ancestrales en relación con la gestión del sistema educativo, servicios de salud, manejo del entorno ambiental, la gestión del hábitat y los sistemas de producción y consumo. 


\section{Objetivo 3: Garantizar los derechos de la naturaleza para las actuales y fu-} turas generaciones

3.4 Promover buenas prácticas que aporten a la reducción de la contaminación, la conservación, la mitigación y la adaptación a los efectos del cambio climático, e impulsar las mismas en el ámbito global.

Objetivo 5: Impulsar la productividad y competitividad para el crecimiento económico sostenible de manera redistributiva y solidaria

5.2 Promover la productividad, competitividad y calidad de los productos nacionales, como también la disponibilidad de servicios conexos y otros insumos, para generar valor agregado y procesos de industrialización en los sectores productivos con enfoque a satisfacer la demanda nacional y de exportación. 5.6 Promover la investigación, la formación, la capacitación, el desarrollo y la transferencia tecnológica, la innovación y el emprendimiento, la protección de la propiedad intelectual, para impulsar el cambio de la matriz productiva mediante la vinculación entre el sector público, productivo y las universidades.

Objetivo 9: Garantizar la soberanía y la paz, y posicionar estratégicamente al país en la región y el mundo

9.4 Posicionar y potenciar a Ecuador como un país megadiverso, intercultural y multiétnico, desarrollando y fortaleciendo la oferta turística nacional y las industrias culturales; fomentando el turismo receptivo como fuente generadora de divisas y empleo, en un marco de protección del patrimonio natural y cultural.

\section{3b) Horizontes epistemológicos}

El segundo aspecto que permitió reflexionar y estructurar el currículo fue el análisis de los horizontes epistemológicos presentes en la profesión. Se evidenció dos horizontes propios de la disciplina y tres paradigmas pedagógicos para la construcción curricular.

A nivel disciplinar se consideró al Diseño Gráfico desde su función estratégica como horizonte de formación y también el Diseño Gráfico como Diseño de Comunicación orientado a construir experiencias visuales significativas. A nivel estratégico se propone el superar dialécticamente las concepciones de Oficio, Arte, Técnica; Disciplina para abordar una concepción en donde el Diseño Gráfico puede ocupar un rol de transformación y generación de innovación organizacional y social. En esta concepción y tomando en cuenta la escalera de Diseño propuesta por el Centro Danes del Diseño en 2001 (DDC, 2016) se propone orientar la formación de los estudiantes para vincular el diseño en las áreas gerenciales y de toma de decisión de las organizaciones. Comúnmente el Diseño se vincula en la etapa final o en las etapas tempranas del proceso de desarrollo de los productos y servicios y los profesionales del Diseño no están preparados para integrarse en las altas direcciones y para incidir en el concepto u orientación del negocio que generar mayores ganancias y rentabilidad. 
Los efectos económicos son más pronunciados en las empresas donde el diseño está firmemente arraigado en inversiones de diseño tanto internas como externas. Con respecto a la posición de las empresas en Design Ladder, una colocación más alta en Design Ladder se asocia con un efecto positivo en las ganancias brutas y un claro efecto positivo en las exportaciones. (DDC, 2016)

Desde la visión del Diseño Gráfico como estrategia se propone que la formación del Diseñador vaya desde la planeación global de acciones tácticas como respuestas directas a necesidades de comunicación gráfica hasta la formulación de procesos proyectuales orientados a generar valor diferencial a nivel estratégico en las organizaciones para mejorar su competitividad.

El segundo horizonte epistemológico propuesto es el Diseño Gráfico como Diseño de Comunicación. Este paradigma del Diseño plantea el pasar de una visión disciplinar a una multi, inter y transdisciplinar. Integrar al Diseño Gráfico otras disciplinas para construir experiencias visuales significativas como último fin del mensaje gráfico y los contenidos relevantes dirigidos por medio de narrativas gráficas. De esta manera esta concepción se preocupa por generar entornos más significativos para que los públicos se involucren, fidelicen, colaboren o consuman los productos o servicios ofertados por las instituciones, empresas u organizaciones satisfaciendo sus más altas exigencias.

El diseño de comunicación es una actividad intelectual, creativa, estratégica, técnica y de dirección. Esta actividad involucra esencialmente la producción de soluciones visuales para problemas de comunicación. El diseño de comunicación se ha convertido en una profesión que incorpora cada vez más las expresiones y los enfoques de otras disciplinas en un resultado visual híbrido y pluridimensional. Hoy, los límites entre las disciplinas de Diseño son más permeables, gracias al uso compartido de herramientas digitales y conocimientos avanzados. A medida que el proceso de trabajo en equipo adquiere una complejidad mayor, los diseñadores de comunicación necesitan redefinir su papel y sus propósitos hacia un contexto de medios de comunicación más amplio, dominado por un modo de intercambio "de muchos hacia muchos"(ICOGRADA, n.d., p. 42)

En este enfoque se integran los conocimientos y áreas de práctica del Diseño Gráfico, por ejemplo: Identidad de marca, señalización, empaque, impresos, productos editoriales, animación multimedia, diseño web, diseño audiovisual, etc. para fomentar experiencias de uso significativas que creen y posicionen marcas de impacto en el imaginario de los públicos. Los públicos al tener gran acceso a la información pueden comparar con mayor rigurosidad y demandan cada vez productos de alta calidad y sobretodo experiencia simbólica y que estén integrados a los distintos medios y canales por los cuales se relacionan: libros, juegos, juguetes, productos, películas, web, aplicaciones, video juegos, entornos, espacios, etc. Otro aspecto importante en los nuevos entornos de comunicación e información digital y en donde la tecnología ha democratizado su acceso de forma masiva es que esta visión plantea el fortalecer las relaciones comunicativas que no se podían lograr en décadas pasadas de los 
mas medias donde el público mantenía un rol pasivo de comunicación y el Diseño Gráfico cumplía estrictamente una función publicitaria. De esta manera el Diseño de Comunicación pone en el centro la experiencia focalizando la conversación, participación, navegación e interacción, el activismo por buenas causas y la postura crítica del lector.

En los mercados actuales, el valor percibido proporciona una medida mucho más exacta del precio que los valores derivados de evidencias tangibles como el trabajo, la ingeniería o la materia prima. En pocas palabras, la manera en que las personas perciben el producto o servicio es lo que realmente influye en el precio que están dispuestas a pagar por ellos....Los diseñadores son capaces de cimentar la comunicación de una marca con experiencias del consumidor que demuestran sus valores de manera tangible. Crean contenidos atractivos y cuentan historias visuales que dan vida a las marcas. Su capacidad de orquestar experiencias que promueven una implicación consensuada les ha valido un lugar en las cúpulas directivas de las empresas en las que trabajan (Yates \& Price, 2016, pp. 6-7)

A nivel curricular se consideró como horizontes epistemológicos a la complejidad sistémica, el constructivismo y al paradigma pedagógico Ignaciano propio de nuestra Universidad en diálogo con las cualidades propias del campo del conocimiento y práctica del Diseño Gráfico. Este, involucra distintos saberes transversales y áreas del conocimiento, lo que permite comprenderse como un quehacer interdisciplinario en su modo de operar y existir.

El núcleo básico metodológico del aprendizaje en Diseño Gráfico es el Taller. Los talleres de Diseño son las unidades espaciotemporales en las que se resuelven los problemas que articulan los núcleos básicos de la disciplina. En los talleres se produce el aprendizaje colaborativo, significativo y contextualizado desde la acción de diseñar, a través de la solución de problemas que se encuentran en la realidad inmediata. El estudiante protagoniza su propio proceso de aprendizaje; el docente solo actúa como facilitador que conduce al estudiante desde criterios teóricos y metodológicos adecuados para el desarrollo de proyectos de comunicación gráfica. Orienta desde una visión humanista, de dignidad humana y social, respeto al medio ambiente y uso de tecnologías apropiadas.

El Diseño Gráfico, como disciplina aplicada, se caracteriza por enfrentarse a problemas de contexto, y por tanto de naturaleza compleja. La realidad es su punto de partida: el diseñador debe atender a un sistema de variables muy diversas, muchas veces contradictorias entre sí, y enfrentarse a la dificultad de buscar una posible solución, que no está determinada de antemano.

Según Larrea de Granados (2015), el horizonte de la complejidad de Edgar Morín aporta a la educación una nueva manera de concebir e interactuar con el mundo. Nos vuelve co-constructores de la historia y de nuevas realidades, demandando a los procesos de aprendizaje, convertirse en una experiencia social que reconoce los elementos biológicos, antropológicos, sociales y culturales, en la cognición de jóvenes y adultos.

En este paradigma complejo sistémico se propone superar las concepciones lineales, estrictamente disciplinares y descontextualizadas. 
La ruptura epistemológica plantea el cambio de una formación exclusivamente disciplinar a otras formas de organización del conocimiento de forma abierta e integrada. Los modelos disciplinares conciben el estudio de la realidad desde una serie de fragmentaciones, cuyas perspectivas del saber son lineales, ordenadoras y predictivas, basándose en el control y la eficiencia tecnocrática que deviene del aparente "dominio" sobre las fuerzas sociales y de la naturaleza... Los nuevos abordajes del conocimiento de carácter multi, inter y transdiciplinarios rompen con estas formas de comprensión de la ciencia y la realidad, planteando la complejidad en los estilos de pensamiento, las integraciones del conocimiento y los saberes, la multi dimensionalidad en los abordajes interpretativos, la poli causalidad y los efectos recursivos de las tensiones, problemas y oportunidades de las realidades sociales y naturales.(Larrea de Granados, 2015, p. 19)

En la visión de la complejidad se inserta la Teoría de Sistemas, que entiende a la realidad como un todo que va más allá de la suma de sus partes; el quehacer del Diseño Gráfico que exige la investigación y diagnóstico, planificación, conceptualización diseño, prototipado, producción, evaluación, implementación, se concibe como una actividad sistémica. El pensamiento sistémico no lineal potencia las condiciones de complejidad e incertidumbre, las articula y genera interpretaciones, diseños, y escenarios de aplicabilidad y ensayo. A su vez, estos escenarios son abiertos, lo que permite la adaptación constante de estrategias y el reconocimiento de la infinidad de soluciones posibles en contextos geográficos diversos. $\mathrm{Al}$ integrar al paradigma constructivista en el diseño curricular, se lo concibe como un enfoque epistemológico cuya premisa central es la interrelación existente entre el objeto de conocimiento y el sujeto que aprende. La corriente constructivista del aprendizaje sostiene, que el individuo, sus aspectos cognitivos, sociales, afectivos y su comportamiento frente al ambiente son el resultado de una construcción propia del conocimiento, gracias a la actuación mediadora del docente.

Las principales premisas del paradigma constructivista que se integran en la elaboración, y sobretodo en la implementación del currículo son:

- El conocimiento no es una representación exacta de la realidad.

- La realidad cambia permanentemente, esto es, los conocimientos solo son abordajes lógicos y ordenados realizados por individuos que interaccionan con el entorno, pero nunca verdaderos, ni unívocos (no hay un solo conocimiento, sino tantos, como abordajes existen de una misma realidad)

- Todo aprendizaje constructivo supone la adquisición de un conocimiento nuevo. Pero en este proceso no se reconoce como válido solo el nuevo conocimiento que se ha adquirido, sino, sobre todo la posibilidad de enlazarlo con aprendizajes previos y desarrollar una nueva competencia que le permitirá generalizar, es decir, aplicar lo ya conocido a una situación nueva.

- Son las aproximaciones a la realidad las que van generando procesos de desequilibrio y adaptación de los sujetos a la misma, produciendo a su vez estructuras (Piaget, 1990), interacciones culturales (Vigotsky; Leontiev; Luria, 2004) 
y organización lógica del pensamiento (Ausubel, 2002), al mismo tiempo que "la producción de significaciones y atribuciones de sentido, que serán expresadas a través del lenguaje" (Ceberio, M; Watzlawick,P, 1998). En (Larrea de Granados, 2015, p. 22)

Finalmente, y como paradigma propio para la construcción curricular es el paradigma pedagógico Ignaciano. La Pedagogía Ignaciana constituye un enfoque sobre el qué y la finalidad del proceso educativo, los roles de los actores que en él intervienen y las orientaciones metodológicas para la ejecución de dicho proceso, atendiendo a los objetivos fundamentales que ha de perseguir la educación en el ámbito de la Compañía de Jesús.

Según Duplá, la Pedagogía Ignaciana no es tanto un método cuanto un espíritu, un enfoque sobre la realidad, que proporciona una visión sobre: el sentido de la vida del hombre, la relación con Dios y con los demás, el uso y sentido de los bienes materiales, el manejo de la libertad (Duplá, 2000, p. 1)

En tanto que, a la luz de los Ejercicios Espirituales de San Ignacio, el Paradigma Pedagógico Ignaciano (PPI, en adelante) es fundamentalmente un planteamiento práctico que proporciona, sobre todo, un método específico para la realización del proceso educativo. Este paradigma contempla cinco aspectos: Contexto, Experiencia, Reflexión, Acción y Evaluación, que no constituyen una receta didáctica aplicable a cada acto de la enseñanza, sino que ayudan a organizar toda la acción educativa. El centro o núcleo del paradigma pedagógico lo constituyen la experiencia, la reflexión y la acción, que se realizan en un contexto y que necesitan una evaluación (Duplá, 2000, p. 2)

El Paradigma Pedagógico Ignaciano es un proceso, consciente y dinámico, que se realiza en cinco etapas, sucesivas y simultáneas, donde cada una de ellas se integra con las demás, de tal manera, que se afectan e interactúan durante todo su desarrollo. La aplicación de este proceso pedagógico no se refiere exclusivamente al proceso educativo a nivel del aula y de la relación educador - educando; es necesario aplicarlo también a todo el entorno institucional que lo soporta ya que de lo contrario podría darse el peligro de contradecir institucionalmente lo que se pretende lograr. Toda la institución educa, el paradigma está al servicio de la gestión total y no solo la del conocimiento (Larrea de Granados, 2015, p. 2) El Paradigma Pedagógico Ignaciano propone una metodología específica para orientar el proceso educativo, mediante la realización de cinco etapas, las cuales se mencionan a continuación:

a) Contextualizar la realidad.

b) Experimentar vivencialmente.

c) Reflexionar sobre esa experiencia.

d) Actuar consecuentemente.

e) Evaluar la acción y el proceso seguido.

Retomando los planteamientos de Granados, en seguida se describen las etapas del mencionado Paradigma: 
Contextualizar. Es poner el tema, el hecho y sus protagonistas en su realidad, en sus circunstancias. La contextualización consiste en situar en su circunstancia al sujeto y a aquel aspecto de la realidad que se quiere experimentar, conocer, apropiar y transformar. Precisamente, el punto de arranque para San Ignacio es situarse en la realidad "ver la historia", es decir, enfrentar la realidad como ella realmente aparece. Esto supone ver los condicionamientos sociales, económicos, políticos y culturales, que pueden distorsionar la percepción y comprensión de la realidad, el dinamismo de la fe y la situación personal del individuo (Larrea de Granados, 2015, p. 3)

Experimentar. La experiencia es la apertura radical del sujeto como individuo y comunidad a toda la realidad. Es toda forma de percepción tanto interna como externa.

La experiencia es la noticia informe y previa, carente aún de cualquier significado que pueda emerger. Deja de ser experiencia en el momento en que es entendida, cuando la persona se responde a la pregunta que le impulsa a sentir, a imaginar, a inquirir, a buscar. En este nivel del Paradigma, el sujeto está presente a sí mismo en cuanto mero receptor de datos, de sus propias operaciones sensibles y afectuosas.

Por lo tanto, la tarea educativa fundamental en este nivel de conciencia consiste en desarrollar, en la persona, la capacidad de atender, de estar atento a percibir la realidad y los fenómenos que están ocurriendo (Larrea de Granados, 2015, p. 5)

Reflexionar. Este tercer elemento del Paradigma es el que más propiamente recoge la actividad intelectual. Es el lugar en que se da la apropiación y por ende su humanización [...]

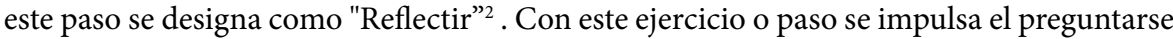
qué es lo que se ha vivido en la experiencia, cuál es su significado, qué relación tiene con cada una de las dimensiones de nuestra vida y de la propia situación.

[...] Entre los procesos de reflexión, distinguimos dos operaciones fundamentales:

a) entender $y$,

b) juzgar (Larrea de Granados, 2015, p. 6)

Actuar. El aporte decisivo de la Pedagogía Ignaciana consiste en desafiar a la persona a dar un paso más: asumir una postura personal frente a la realidad y a actuar en coherencia con ella.

La acción es entendida como la manifestación operativa de una decisión libremente asumida para la transformación de la persona y de la realidad institucional y social en que vive.

Dentro del Paradigma, esta definición de la acción, como su cuarta etapa, se operacionaliza en dos momentos:

a) decisión y

b) operacionalización (Larrea de Granados, 2015, p. 7)

Evaluar. La evaluación se entiende como una revisión de la totalidad del proceso pedagógico seguido a lo largo de cada uno de los pasos del paradigma, para verificar y ponderar 
en qué medida se han realizado fiel y eficientemente y, por otra parte, en qué grado se han obtenido los objetivos perseguidos, en términos de cambio y transformación personal, institucional y social.

La evaluación, por lo tanto, tiene en consideración necesariamente dos aspectos

a) Revisión de procesos y

b) Ponderación y pertinencia de resultados (Larrea de Granados, 2015, p. 8)

\section{3c) Núcleos básicos de integración curricular}

Los núcleos básicos son los conocimientos cardinales de las disciplinas que permiten la integración de los métodos, lenguajes, procesos y procedimientos que las estructuran, su producción y aplicación está orientada a la resolución de los problemas de la ciencia y de la realidad relacionados con la profesión. Por tanto, los componentes del núcleo de una disciplina siempre deberán responder a redes semánticas y sintácticas (Larrea de Granados, 2015, p. 35)

Para la carrera de Diseño Gráfico los núcleos básicos de las disciplinas son los definidos por el profesor Jaime Franky en el libro el Acto de Diseñar (Franky Rodriguez, 2015, pp. 66-67) en donde se definen como sistema de referentes y constituyen redes de relaciones en donde el núcleo central que es la pre configuración teje estas redes en la práctica de la construcción de mensajes gráficos para los públicos definidos y de acuerdo a los problemas del contexto con los otros núcleos que se encuentran alrededor oscilando. Los núcleos propuestos son:

- Núcleo: Preconfiguración (Proyecto de Diseño Gráfico)

- Núcleo: Sostenibilidad Ambiental - Cultural

- Núcleo: Innovación

- Núcleo: Ser humano (razón de ser del diseño)

- Núcleo: Recursos organizacionales y productivos

- Núcleo: Estética

\section{3d) Vinculación del currículo con las tecnologías}

A lo largo del programa de estudios de Diseño Gráfico se afianzan los conocimientos en herramientas tecnológicas para generar resultados más efectivos y eficientes. Los estudiantes exploran procesos digitales y análogos de impresión, así como, paquetes computacionales de vanguardia para la configuración y reproducción de proyectos gráficos. Las tecnologías impartidas ayudan a representar y materializar las soluciones proyectuales y mensajes gráficos con el fin de consolidar las áreas de práctica profesional de Diseño para la información, persuasión, educación, administración, de identidad gráfica, entre otras. Mediante estas se dará respuesta a los problemas y necesidades descritas en los lineamientos, políticas y objetivos del Plan Toda una Vida 2019, necesidades de los sectores estratégicos y de interés público. 
Las herramientas que se integran en la formación profesional y que permiten al estudiante aprender en un entorno actualizado, con tecnologías de punta para medios virtuales e impresos, son:

\section{Para retoque y edición fotográfica}

Se utilizan programas que funcionan a partir de imágenes rasterizadas. A cada píxel se le asigna un color, y entre todos componen una obra visual. La imagen rasterizada permite una gran precisión de matices, que pueden ser manipuladas a través de las herramientas. Se utiliza, por ejemplo, Adobe Photoshop.

\section{Para ilustración y dibujo figurativo}

Las aplicaciones de dibujo vectorial descomponen una ilustración en sus mínimas partes geométricas, se emplea, por ejemplo, Adobe Illustrator.

\section{Para maquetación y composición}

Al maquetar es necesario distribuir en un lienzo todos los elementos que la conforman (i.e. texto, ilustraciones, imágenes, animaciones, botones, entre otras). Las publicaciones pueden ser elaboradas para impresos como libros o para documentos digitales como aplicaciones móviles, por ejemplo, Adobe InDesign y Adobe XD.

\section{Para diseño web}

Para controlar los aspectos gráficos de la creación de un sitio web, se aprenden lenguajes HTML y CSS en herramientas de desarrollo como Adobe Dreamweaver. Adicionalmente, se incorporan tecnologías de software libre para administrar contenidos como por ejemplo Joomla o Wordpress, y lenguajes para el uso de bases de datos como PHP y SQL.

\section{Para la edición de medios audiovisuales}

Se emplean tecnologías para la edición de video en donde se integran escenas animadas, efectos especiales, música, diálogos o efectos de sonido. Se emplean programas como por ejemplo Adobe Animate, Adobe Premiere Pro, Adobe After Effects, y Adobe Audition.

\section{Para producción de nuevos medios}

Se exploran lenguajes de programación para la producción de gráficos generativos en base a algoritmos matemáticos, y sistemas visuales interactivos que respondan a diferentes eventos. Se emplean programas de software libre como Processing, P5js y herramientas de hardware libre como por ejemplo Arduino.

\section{Para impresión}

El tránsito de la imagen en computadora a la imagen impresa se realiza mediante dos procesos técnicos:

- El Tramado de la imagen, o su conversión en un conjunto de puntos.

- La Separación de los colores, o conversión de cualquier matiz de la imagen en los componentes básicos de color usados en la imprenta: cian, magenta, amarillo y negro. 
Desprendiéndose de esto, el estudiante recorre por una serie de métodos actuales de impresión, que le permiten tener los conocimientos pertinentes para finalizar adecuadamente un proyecto de Diseño Gráfico. Se incorporan a la formación del Diseñador Gráfico conocimientos sobre tecnologías offset, láser, inkjet e índigo.

De igual manera y tomando en cuenta los cambios que inciden en la digitalización de la información y en donde las tecnologías de impresión también avanzan, las tecnologías tradicionales vuelven a tener gran valor ya que poseen gran valor expresivo y simbólico. De esta manera se emplean y hace énfasis en recuperar tecnologías tradicionales como:

- Tipos móviles (imprenta mecánica)

- Serigrafía, flexografía, huecograbado y rotograbado

- Grabado y estampado

- Intaglios, sellos y marcas

- Dibujo e ilustración

- Encuadernación

- Acabados manuales y especiales

- Ingeniería del papel y pop art., etc.

Estas tecnologías tradicionales actualmente se fusionan con tecnologías digitales para lograr productos con alto valor simbólico y funcional que promueven como ya se ha dicho nuevas experiencias de lectura y comunicación.

\section{3e) Actores y sectores a los que se dirige la propuesta curricular}

Las áreas de práctica profesional del Diseño Gráfico (Frascara, 2012, pp. 121-152) que son: información, persuasión, educación, administración e identidad, aportan con un sinnúmero de canales de la comunicación visual y que, a través de mensajes gráficos y la producción seriada de piezas de comunicación, buscan contribuir con la mejora en la calidad de vida de los actores involucrados en el proceso mediante la atención a las necesidades y problemáticas comunicativas.

Las acciones de comunicación gráfica se dirigen principalmente a la población económicamente activa (empleados públicos y privados), quienes son la audiencia que asisten a eventos, cursos, capacitaciones (culturales, deportivos, académicos, políticos, económicos, entre otros). Otra parte de los actores y beneficiarios del proceso de comunicación son poblaciones vulnerables de diversos sectores sociales (niños, adolescentes, adultos mayores, personas con discapacidad).

En cuanto a los sectores que atiende el Diseño Gráfico son los generadores de transformación social y se los reconoce dentro de un contexto social delimitado, en este contexto se identifican básicamente a) el sector privado que se compone de las empresas y las organizaciones cuya propiedad no es estatal; b) sector social como responsable de conceptualizar, preparar y apoyar la ejecución y supervisión de operaciones relacionadas a temas de 
género, diversidad, educación, salud, ciencia y tecnología, y; c) sector público compuesto por corporaciones, instituciones y oficinas del Estado, propiedad de todos los habitantes. Este contexto social se inscribe en el concepto de Aldea Global que es influida por las consecuencias de la información inmediata de todo tipo de acontecimientos.

Los profesionales formados en la PUCE a nivel nacional atienden principalmente a los gobiernos provinciales y municipales a los que se pertenecen (zona 9 - Distrito Metropolitano de Quito, zona 4 - Santo Domingo de los Tsáchilas y Manabí; y zona 1 - Esmeraldas, Imbabura y Carchi). Las necesidades de comunicación y producción gráfica en el ámbito comercial, industrial y emprendimientos son los sectores directamente beneficiados con la formación de profesionales en Diseño Gráfico.

Otro aspecto importante, como lo destaca la UNESCO en su informe sobre la Economía Creativa (2013), las industrias culturales y creativas a más del valor económico, son reconocidas por el papel que desempeñan en la producción de nuevas tecnologías o ideas creativas y sus beneficios sociales. En distintos aspectos, se destaca al Diseño (en sus distintas clasificaciones), las artes creativas, la industria editorial, la publicidad, las artes gráficas, la industria papelera, el software y equipos de edición e impresión como fuentes de intervención para los trabajadores creativos quienes a menudo son parte de una organización más amplia y cuyo proceso es iniciado por gerentes, emprendedores, productores o intermediarios que en su mayoría serán los formados en esta carrera de Licenciatura en Diseño Gráfico. Finalmente es importante destacar el compromiso que el Diseño Gráfico tiene con el sector social en donde muchas necesidades prioritarias que se delinean en el Plan Nacional de Desarrollo 2017 - 2021 - Toda una vida mediante sus objetivos y en los sectores estratégicos. Desde esta perspectiva la profesión del Diseño Gráfico debe estar comprometida con su tiempo y contexto, así, muchos problemas pueden ser resueltos con un apropiado enfoque de comunicación y diseño sensible socialmente. Por ejemplo, se puede lograr una correcta señalización en espacios públicos y para el transporte público, así como de comportamiento en áreas de vulnerabilidad como la salud preventiva, la violencia de género, intrafamiliar, la participación ciudadana, los derechos pluriculturales por mencionar algunos. Se puede también promover la lectura para mejorar los índices de la calidad de educación nacional, en este ámbito los diseñadores gráficos pueden participar en la creación de libros que mejoren la experiencia simbólica y de aprendizaje de los niños considerando el contexto nacional. Además, el Diseño Gráfico puede contribuir a dar forma al escenario visual de la cultura nacional y expresar identidad en productos, servicios, lugares, etc. En nuestro país hay una amplia gama de expresiones culturales que configuran el imaginario visual y deben ser valoradas, recuperadas y promocionadas. El desarrollo turístico es considerado también un sector estratégico y en este ámbito la contribución profesional se puede realizar en gran forma para mejorar las experiencias de los turistas y la fidelización con la marca país. Es imprescindible reconocer la importancia del Diseño Gráfico para la sociedad y su aporte para una mejor calidad de vida de las personas, creando incluso un sentido del deber y preocupación por mejorar nuestra realidad. 
3f) Tendencias de desarrollo incluidas en los campos de estudio y de actuación de la profesión

Las tendencias de desarrollo local que están incluidas en los campos de estudio y actuación de la carrera de Diseño Gráfico responden principalmente a los ejes que propone la transformación productiva desde el Plan Nacional de Desarrollo 2017 - 2021 que se centra en los siguientes aspectos:

- Contar con nuevos esquemas de generación y redistribución de la riqueza.

- Reducir la vulnerabilidad de la economía ecuatoriana

- Eliminar las inequidades territoriales

- Incorporar a los actores que históricamente han sido excluidos del esquema de desarrollo de mercado.

De igual forma los aspectos fundamentales del Plan Nacional de Desarrollo que promueve:

- Construcción de ciudadanía

- Descentralización

- Equidad e inclusión

- Calidad de vida

- Fomento de capacidades

- Espacios de encuentro

- Fortalecimiento de la identidad

- Justicia y seguridad integral

- Cuidado de la naturaleza

- Sostenibilidad

- Economía solidaria

- Trabajo digno

- Soberanía

- Integración regional y mundial

Las tendencias de desarrollo regional y global que se plantean como campos de estudio y actuación de la profesión parten de la propuesta de (Rodríguez Morales, 2004, pp. 49-52) en donde estas tendencias tienen las siguientes directrices:

- la globalización

- las nuevas tecnologías

- la nueva economía

- la ecología

- la nueva cultura

- la brecha social existente en nuestra región 
La globalización plantea sobre todo problemas de índole ético y de concepción de identidad. La conservación y respeto de tradiciones de ciertos grupos sociales que posiblemente pueden estar en contra de la tendencia globalizadora exige reflexiones constantes. A nivel de identidad se plantea la dicotomía entre diseñar para grupos con identidad cultural específica vs proyectar para un mundo global abstracto y marcado por tendencias de consumo. Esta postura rebasa los aspectos estilísticos y se puede enmarcar también desde una visión estratégica.

Las nuevas tecnologías modifican nuestro estilo de vida constantemente y la manera en que nos relacionamos socialmente y con el medio ambiente. A nivel profesional proponen permanentemente cambios en la producción con posibilidades impensadas. El acceso a la información ya no es una barrera, pero si su discriminación, análisis y relevancia. Permanentemente las tecnologías cuestionan también la importancia de seguir aprendiendo y empleando técnicas antiguas frente a los desarrollos novedosos que proponen.

La nueva economía que crece constantemente a través de los negocios en línea llamados e-business y e-commerce plantean nuevos retos en la comunicación visual y en la disposición de productos y servicios. La velocidad de acceso, codificación visual y facilidad de lectura son cada vez más desarrolladas para promover una mayor ventaja competitiva y lograr consumidores fidelizados y satisfechos.

La ecología ha evidenciado la crisis medioambiental que sufre nuestro planeta y nos responsabiliza como diseñadores a pensar como mitigar los estilos de vida orientados al consumismo y empleo ineficaz de los recursos. El Diseño al ser un actor fundamental en moldear la cultura debe promover responsablemente nuevos hábitos y valores humanos que equilibren con mayor brevedad la brecha ecológica.

La nueva cultura que emerge en la virtualidad mediante las tecnologías demanda al diseño la posibilidad de construir nuevos lenguajes visuales, entender nuevas formas de comportamiento que tienen demandas emergentes y en continuo cambio. La digitalidad atraviesa todas las actividades humanas con mayor velocidad y promueve nuevos roles en las personas y sus comportamientos que desde el Diseño Gráfico deben ser comprendidos para facilitar y proveer mejores formas de acceso a los que se encuentran menos conectados. La nueva cultura se forma actualmente desde la alfabetización digital.

Finalmente, la brecha social que existe en nuestra región pone un indicador de desarrollo a donde el diseño debe contribuir decididamente. La cobertura de necesidades básicas de educación, salud, vivienda y alimentación son emergentes y el Diseño Gráfico puede aportar decididamente en estas áreas. 


\section{3g) Aspectos de la demanda ocupacional que se toman en cuenta para el diseño curricular.}

De acuerdo con la demanda ocupacional para la Carrera de Diseño Gráfico, la disciplina responderá de forma general a las expectativas y necesidades vinculadas con las áreas de práctica profesional en el diseño para la información, persuasión, educación, administración e identidad gráfica desde una perspectiva de Diseño Estratégico y Diseño de Comunicación.

El análisis de la demanda ocupacional de la profesión está basado en el estudio a graduados y empleadores realizado por la Carrera en 2015, en el seguimiento a graduados por parte de la Unidad de Titulación (períodos académicos 2016_2, 2017_01, 2018_S1,2018_ S2 y mitad del 2019_S1. En total: 57 graduados). y la encuesta levantada en el encuentro de graduados de Diseño y Diseño Gráfico (19 asistentes) El estudio permite determinar el escenario donde se desenvuelven los profesionales de la Carrera de Diseño Gráfico.

Los graduados de la Carrera de Diseño Gráfico de la sede matriz se desempeñan laboralmente en: Relación de dependencia 49\%, Freelance 24\%, Emprendimiento $9 \%$ y no trabajan 18\%. Con un rango salarial: 385 - 500 dólares, 37\%; 501 - 1000 dólares, 59\% y $1001-1500,4 \%$. En cuanto al nivel que ocupa en los puestos de trabajo es: Operativo 9\%, Mando medio 18\%, Directivo 0\% y Propietario 73\%. Lo que demuestra la importancia del profesional especialmente en el sector productivo de la sociedad.

Las áreas en las que se desempeñan los profesionales concuerdan con los campos de formación de la carrera ya que el $77 \%$ se desempeñan en diseño gráfico, persuasión, información y educación, por ejemplo, realizando trabajos de imagen corporativa, editorial, multimedia y gestión de proyectos de diseño; el 14\% vinculada al área de comunicación, marketing y publicidad; el $4 \%$ a la docencia de diseño y el $5 \%$ restante realiza actividades ajenas a la formación profesional.

\section{3h) Funciones y roles que desempeñarán los futuros profesionales}

De acuerdo con el estudio de pertinencia elaborado en donde se integran los resultados del seguimiento a graduados, los roles que desempeñan los Diseñadores Gráficos en los escenarios laborales son:

- Arte finalista y control de procesos de producción gráfica

- Ilustración y fotografía

- Dirección y ejecución de proyectos

- Dirección creativa

- Gestión de Diseño

- Investigador en comunicación gráfica

- Asesoría en proyectos de comunicación gráfica

- Emprendedor en las áreas de negocios creativos 
En relación con lo antes mencionado, los profesionales de la Carrera de Diseño Gráfico de la PUCE, en concordancia con su perfil de egreso, estarán en la capacidad de desempeñarse en las siguientes funciones:

- Diseñador para proyectos de información

- Diseñador para proyectos de persuasión

- Diseñador para proyectos de educación

- Diseñador para proyectos de administración de información

- Diseñador para proyectos de identidad gráfica

- Diseñador para proyectos de Diseño Estratégico.

- Diseñador para proyectos de Diseño de comunicación

Las competencias del Diseñador Gráfico de la PUCE que evidencia su perfil de egreso y por medio de las cuales podrá cumplir sus funciones y roles en los escenarios laborales son:

a. Comprensión holística, estratégica ${ }^{3}$ e histórico crítico del contexto y la profesión que le permita situar las problemáticas o necesidades y dar respuestas efectivas desde una visión teórica y conceptual adecuada.

b. Efectividad en el planteamiento de soluciones de Diseño de comunicación que se orienten a la experiencia de los usuarios como al desarrollo de ventajas competitivas para organizaciones y entornos productivos desde el pensamiento de Diseño.

c. Capacidad intuitiva y creativa para la ideación, representación y producción de propuestas conceptuales innovadoras, así como capacidad lógica de análisis y síntesis de la información para orientar las soluciones de forma efectiva.

d. Dominio de tecnologías digitales y tradicionales para la ideación, representación y producción eficiente tomando en cuenta la calidad de los proyectos en el uso de materiales, procesos y costos con criterios de impacto ecológico.

e. Destrezas de investigación para el desarrollo de soluciones y como base para el aprendizaje continuo, los nuevos planteamientos, el desarrollo de nuevas tecnologías o aplicaciones innovadoras de tecnologías existentes y nuevas iniciativas.

f. Capacidad de gestión, emprendimiento e innovación apuntando a la excelencia y por medio de una actitud responsable, ética, honesta y con integridad.

g. Actitud de escucha, apertura y diálogo para la construcción de relaciones cordiales, respetuosas e interculturales, en procura del desarrollo personal y colectivo.

Los resultados y logros de aprendizaje que permite la construcción de cada una de estas competencias se describen en el apartado perfil de egreso. 


\section{4) Planificación Curricular}

\section{4a) Objeto de estudio}

La Carrera de Diseño Gráfico estudia, la configuración de mensajes gráficos y las relaciones, interacciones, condiciones y problemas que resultan entre el design (mensaje gráfico), sus autores, codificadores y públicos destinatarios definidos en un contexto y momento de enunciación específico. (Muñoz, 2009, pp. 9-13) Este estudio exige la compresión de los elementos morfológicos y del lenguaje visual, las concepciones teóricas, conceptuales y metodológicas, el uso apropiado de tecnologías y el impacto que generan estos en el entorno social, cultural, económico, tecnológico, etc.

\section{4b) Lo que se propone transformar con la propuesta curricular}

Con la formación profesional de Diseñadores Gráficos de la PUCE se quiere en primera instancia enfrentar los seis problemas del contexto definidos y mencionados en el apartado $3 \mathrm{a}$.

El enfrentar estos problemas exige también transformar en algún grado las concepciones y relaciones sociales existentes sobre la profesión. Dentro de este aspecto se identifican los siguientes problemas:

- Escasa atención de los Diseñadores a problemas de comunicación gráfica de los sectores sociales y productivos definidos en los planes nacional y locales de desarrollo.

- Insuficiente especialización profesional en el Diseño Gráfico que les permita a los graduados diferenciarse frente a la demanda y oferta laboral.

- Sobrevaloración del Diseño Gráfico como herramienta publicitaria, técnica y creativa y escasa comprensión de su capacidad estratégica para mejorar la competitividad organizacional.

A nivel de la formación del Diseñador Gráfico se requiere transformar las concepciones y dificultades observadas en la enseñanza de la profesión que desde una perspectiva dialéctica permitan proponer una formación acorde a los tiempos. Estas concepciones y dificultades son las siguientes:

- Deficientes competencias teóricas y metodológicas en el desarrollo de proyectos de Diseño Gráfico versus la sobrevaloración del aprendizaje de software de edición.

- Reducida comprensión del Diseño Gráfico como instrumento para agregar valor simbólico diferencial que mejoren los entornos sociales, culturales y productivos.

- Escasa conexión de los contenidos de las asignaturas que permitan comprensiones significativas para la fundamentación y aplicación efectiva de los conocimientos del Diseño Gráfico.

- Bajo nivel en la comprensión del contexto, la necesidad del comitente y expectativa del público destinatario al configurar los mensajes gráficos. 
- Poca efectividad en la conceptualización e ideación creativa de los proyectos gráficos por desconocimiento y aplicación de técnicas creativas y herramientas teóricas.

- Baja comprensión del mensaje gráfico y sus funciones comunicativas (informativa, didáctica y persuasiva)

- Sobrevaloración de la dimensión estética y de apariencia en la configuración de los productos gráficos.

- Poca preocupación e interés sobre los aspectos: contractuales, técnico- productivo, de propiedad intelectual, costos, venta y comercialización de los productos de Diseño Gráfico.

- Escasa integración de los proyectos y prácticas de aprendizaje a resolver problemas concretos de los sectores productivos y culturales como Pymes y organizaciones sociales y culturales.

- Poca responsabilidad y análisis sobre el uso de los recursos y tecnologías de impresión, producción gráfica y audiovisual.

- Reducido interés por la investigación formativa orientada a la producción de conocimiento, reflexión crítica y enseñanza del Diseño.

En función del diagnóstico sobre las debilidades de las Carreras de Educación Superior realizado por el CES, la Carrera intervendrá en la transformación de otros aspectos, tales como:

- Dificultades en el proceso de graduación. Estudiantes que egresan y no obtienen su título.

- Itinerarios diversos que no han permitido el libre tránsito de los estudiantes entre las universidades.

- Limitada actividad investigativa, lo que ha repercutido en que el país sea un simple reproductor de conocimiento.

- Excesiva oferta de pregrado y casi ninguna para posgrado.

- Programas desvinculados de los requerimientos del sector educativo y de la sociedad.

- Deficiente formación de docentes con enfoques de género, de derechos individuales, colectivos y de la naturaleza, intergeneracional, intercultural, étnico e inclusión social.

\section{4c) Orientaciones metodológicas generales para la transformación de los proble- mas de la profesión.}

A fin de lograr la transformación de los problemas referidos a la profesión y enunciados anteriormente, se aplicarán las siguientes orientaciones metodológicas y aplicaciones:

Análisis de casos. En esta orientación metodológica se plantean situaciones prácticas y concretas de la vida profesional, a través de casos de estudio, en los que el estudiante entrenará su capacidad de análisis y síntesis, así como también el planteamiento de respuestas y soluciones a los problemas planteados. 
E-learning: Los procesos de aprendizaje y enseñanza a través del internet mediante el uso de las tecnologías de información y comunicación (internet, bases de datos, libros virtuales, aulas virtuales, tecnología multimedia, etc.) revolucionan constantemente las concepciones en la enseñanza del Diseño. Esta orientación promueve que desaparezcan las barreras espaciotemporales, la formación es más flexible, el alumno es el centro, el profesor es un facilitador del proceso, los contenidos exigen y permiten ser actualizados permanentemente y la comunicación entre actores es constante. Esta orientación promueve aprendizajes cada vez más significativos.

Aprendizaje basado en problemas. (ABP) En esta orientación metodológica, se plantea un trabajo en equipo para el planteamiento, análisis, discusión y obtención de soluciones viables, que apunten a la resolución de problemas reales planteados en escenarios de aprendizaje. Los problemas permiten formar competencias efectivas en los estudiantes y en donde el aprendizaje es auto dirigido y promueve la investigación y desarrollo de capacidades autónomas de los estudiantes.

Aprendizaje experiencial: En esta metodología se considera al aprendizaje como un proceso mediante el cual el conocimiento se crea en base a la transformación de una experiencia. Esto exige que los estudiantes estén implicados en una situación experiencial en donde construyan y reorganicen el conocimiento por medio de sus niveles de representación, acorde a sus realidades, experiencias anteriores, valores, normas y reglas. Esto sucede siempre y cuando estén alertas, reflexivos y conceptualicen la realidad para convertirla en información significativa.

Este modelo de aprendizaje integra a las giras de observación y visitas de campo, las prácticas y actividades de vinculación con la comunidad para la observación in situ de los problemas que deben abordarse, y cotejarlos con la realidad espacial existente y la aplicación adecuada de los aprendizajes teórico-prácticos.

Proyectos: Este método es el más empleado en Diseño, estructura las competencias profesionales y emplea el método proyectual como guía mediante sus etapas de investigación, desarrollo y validación. El proceso dentro del aula en donde se aplica el método de proyectos es guiado y acompañado en clase por el docente en base a una problemática o necesidad concreta en los ámbitos de diseño de información (editorial), identidad de marca y señalización, diseño de nuevos medios (multimedia) y diseño estratégico empleando medios impresos y digitales. Los estudiantes en este proceso son los actores centrales y la evaluación les exige fundamentalmente confrontar las soluciones propuestas con las demandas definidas en la etapa de investigación.

Proyectos interdisciplinarios en equipo: Este método es una variante del anterior, pero a aplicarse con la intervención multi, inter, y transdisciplinaria (Diseño Gráfico, Diseño de Producto, Diseño Textil e indumentaria, Diseño interior, Arquitectura, Artes Visuales, Educación, Salud, Marketing, Negocios y Administración, Biología, etc.) Esta visión es de trascendental importancia ya que se busca lograr proyectos cuyas soluciones posean mayor viabilidad de aplicación ya que las consideraciones son más complejas, dinámicas y 
con abordajes integrados pensando siempre en el contexto y los de sus beneficiarios como el eje de integración y no los conocimientos disciplinares.

En el caso de la carrera de Diseño Gráfico en la sede matriz se promueve la integración con Diseño de Productos en el Taller de Diseño Estratégico y se ha continuado con la integración en proyectos de desarrollo de emprendimientos entre Diseño Gráfico y Administración de empresas.

Otros métodos como el aprender sirviendo (service learnig), aprendizaje cooperativo y recíproco, evaluación auténtica, participación tutelada en investigación, formación práctica in situ se consideran dentro del aprendizaje del Diseño Gráfico, pero en momentos específicos por lo cual no se desarrollan con amplitud.

\section{4d) Orientaciones del conocimiento para la construcción del objeto de estudio.}

Las orientaciones y saberes que toma en cuenta la construcción del objeto de estudio del Diseño Gráfico se fundamentan en la investigación transdisciplinar (Sexe, 2001, pp. 6566) y proponen una concepción de estudio de relaciones interdependientes, dinámicas y en permanente cambio en donde el conocimiento es un proceso de construcción social e individual de sentido. El estudio de las relaciones que se producen entre los emisores, codificadores y destinatarios del mensaje gráfico en un contexto definido permite comprender la multiplicidad de variables complejas que emergen en cada una de ellas y conformar un cuerpo teórico y metodológico adecuado para su comprensión y aplicación dentro de la formación del Diseñador Gráfico.

La comunicación, antes que una teoría inacabada o una ciencia especial, se sitúa en un campo donde confluyen ciencias humanas, sociales, de la subjetividad, que dan cuenta de las distintas producciones de sentido. El diseño también permite ser pensado como un campo, como un lugar de articulación y condensación de subjetividades... Se trata, de pensar en términos de construcción social. Entre emisores y receptores, entre signos, entre significantes, entre significados, hay una especie de espesura "blanda", un fuelle, que autores como Deleuze han denominado entre. Ese entre está cargado de dispositivos de subjetividad y la comunicación o el diseño resultan construidos. Son un constructo. (Sexe, 2001, pp. 66-67)

Esta orientación de acuerdo con Jorge Luis Muñoz (2009) no tiene un afán de intelectualización o de sistematización ya que el Diseño en sí mismo tiene una gran carga artística y poética que va más allá del código del mensaje utilizado ya que trasmite un valor simbólico y construye imaginarios afectivos y experienciales. El objeto de estudio planteado permite incorporar al análisis las representaciones, premoniciones e intuiciones que son funciones cerebrales propias del pensamiento de Diseño, de igual forma aborda la comunicación gráfica desde la efectividad del mensaje y construcción de experiencias simbólicas acordes a las necesidades de los destinatarios definidos donde la creatividad tiene una dirección y objetivo. 
El Diseñador no solo crea mensajes gráficos que impacten los sentidos, sino que busca construir sentido y significado por lo cual dentro de los saberes que debe incorporar para cumplir su quehacer se encuentran:

- Manejo de técnicas de representación, ilustración y dibujo, así como materiales para la producción.

- Posesión de sentido estético en el uso de la forma y espacio, color, imagen, tipografía y composición.

- Manejo de software e instrumentos de producción y representación de diseño

- Conocimientos de historia y sociedad, contexto tecnológico y cultura.

- Manejo de técnicas y estrategias de comunicación.

- Manejo de capacidades cerebrales y mentales lógicas e intuitivas.

- Comprensión de entornos competitivos y sociales.

- Empleo de metodologías de investigación centradas en las personas.

- Conocimiento de teorías de comunicación, semiología y retórica.

- Capacidad para presentar proyectos y realizar su negociación.

De todos los saberes que proveen la antropología, sociología, comunicación, computación, semiología, retórica, psicología, publicidad, marketing, administración, negocios, gestión, planificación estratégica, estudios culturales, pedagogía, didáctica, etc. solo emplea los que tengan relación directa con la finalidad del quehacer del Diseño Gráfico que es la configuración de mensajes gráficos para destinatarios definidos con alto valor simbólico, que promuevan experiencias significativas y contribuyan a enriquecer la cultura material y calidad de vida.

\section{4e) Competencias (habilidades, destrezas y actitudes)}

Las habilidades y destrezas teóricas, prácticas, metodológicas y actitudinales tendrán su trasfondo en los horizontes pedagógicos definidos, los cuales hacen posible la incorporación del diálogo de saberes ancestrales, cotidianos y tradicionales, de inclusión, diversidad y enfoque de género, por su visión integral de la realidad.

Habilidades y destrezas teóricas:

- Conocer y comprender las distintas manifestaciones culturales y sociales, reconociendo la naturaleza humana en sus distintas dimensiones, fundamentados en las bases teóricas que permitan la identificación de los diversos contextos socioculturales.

- Reconocer y comprender las corrientes teóricas para la inclusión social, complementado con el análisis crítico del enfoque de género como una construcción social, cultural, histórica y política. 
Habilidades y destrezas metodológicas:

- Vincular y desarrollar procesos de comunicación gráfica que integren y potencien la visión intercultural para contribuir al desarrollo de las poblaciones y grupos más vulnerables y lograr la integración social y el buen vivir.

- Desarrollar adecuados procesos metodológicos que permitan identificar y valorar las distintas variables de los grupos sociales, reconociendo a la interculturalidad y el enfoque de género como una característica inherente a la realidad sociocultural del país.

Habilidades y destrezas actitudinales:

- Desempeñar los procesos académicos con responsabilidad social, promoviendo principios éticos a través del adecuado manejo de la información y la comunicación, amparados en el respeto, el derecho y la igualdad de género.

- Reflexionar y valorar la diversidad sociocultural, sus características y manifestaciones, y asumir una postura crítica frente a factores de exclusión social y condiciones de violencia que afectan el principio de interculturalidad y enfoque de género.

\section{5) Campos de estudios}

\section{5a) Integraciones curriculares}

La Carrera de Diseño trabajará las integraciones curriculares mediante la implementación de:

A. Proyectos de integración de saberes: ubicados a partir de la unidad de formación básica, y organizados en el área de praxis profesional, en los que se trabaja directamente con la visión de integración de saberes. Los proyectos de integración se plantean como nivel, en base a temáticas definidas y en donde permiten organizar el proceso metodológico de todas las asignaturas. Se proponen dos proyectos simultáneos y proyectos cortos sin cliente y largos con cliente de acuerdo con el grado de complejidad de acuerdo con Jorge Frascara. (2012)

B. Proyecto de investigación: corresponde al eje investigativo de la formación y empieza desde la unidad de formación básica, y permite la puesta en ejecución de las competencias relativas a la investigación alineada a la integración de los distintos saberes. En la Unidad de integración curricular se hará énfasis en la elaboración de proyectos vinculados a resolver las necesidades o problemáticas del contexto que se concretan en el proyecto de titulación.

C. Prácticas laborales: incluidas en la Unidad profesional a partir del sexto nivel, se trabajan independientemente, con un enfoque especial en que sean el espacio privilegiado que une la academia con el campo profesional. 
A continuación, se describirán las redes de aprendizaje por cada uno de los niveles:

\section{NIVEL 1- Red de Aprendizaje 1: Contextos y fundamentos del Diseño}

Al final de esta red el estudiante estará en capacidad de: Entender el contexto histórico donde surge y se desarrolla el Diseño, y abordar los fundamentos del Diseño para construir mensajes de comunicación gráfica desde una perspectiva metodológica intuitiva.

\section{NIVEL 2- Red de Aprendizaje 2: Mensaje Gráfico}

Al final de esta red el estudiante estará en capacidad de: Construir mensajes de comunicación gráfica comprendiendo su codificación por medio de la aplicación de los elementos básicos del Diseño Gráfico, sirviéndose además de distintos lenguajes como la representación gráfica y la fotografía, y el apoyo de herramientas digitales.

\section{NIVEL 3 - Red de Aprendizaje 3: Unidad de Sentido}

Al final de esta red el estudiante estará en capacidad de: Construir unidades de sentido simbólicas mediante mensajes gráficos con características principalmente persuasivas y para públicos objetivos definidos. La construcción simbólica se realizará mediante la apropiación de la estructura del signo y del mensaje, utilizando la iteración narrativa y la estructuración de Conceptos de Diseño que permitan lograr comunicación efectiva. Además, el apoyo de lenguajes y herramientas digitales permitirá la composición del mensaje y edición digital de artes para impresión.

\section{NIVEL 4 - Red de Aprendizaje 4: Diseño de Información}

Al final de esta red el estudiante estará en capacidad de: Comprender los elementos de estructuración, planeación, maquetación y disposición para que el estudiante pueda componer distintos proyectos en el ámbito informativo especializado y ligados a un concepto transversal expresado en cada aspecto de un proyecto gráfico que toma en cuenta las condiciones del medio y el público al que se dirige.

\section{NIVEL 5 - Red de Aprendizaje 5: Diseño de Identidad Gráfica}

Al final de esta red el estudiante estará en capacidad de: Construir propuestas conceptuales y estratégicas de Diseño de identidad de marca mediante el uso de herramientas creativas y de diagnóstico, propuestas enfocadas en el área del Diseño de persuasión y de información con un alto valor comunicativo y simbólico. Además, se complementa con el análisis de la relevancia de la metodología proyectual en la generación de los discursos sociales, y el amplio campo de desarrollo del Diseño de nuevos medios en donde se plantean nuevas reflexiones teóricas a nivel comunicacional.

\section{NIVEL 6 - Red de Aprendizaje 6: Diseño para nuevos medios}

Al final de esta red el estudiante estará en capacidad de: Proponer soluciones de comunicación visual orientadas a informar, formar, entretener o administrar con énfasis en la usabilidad e interacción en los nuevos medios, para generar mayor eficiencia comunicativa en la relación de los usuarios con las TICs, que le permiten al Diseño Gráfico nuevos 
ámbitos de aplicación en donde puede proponer experiencias emocionales de comunicación basadas en la interacción y usabilidad.

\section{NIVEL 7 - Red de Aprendizaje 7: Diseño Estratégico}

Al final de esta red el estudiante estará en capacidad de: Plantear soluciones creativas, enfocadas desde la gestión del Diseño como estrategia y desde el trabajo interdisciplinario con diseñadores de productos, para la resolución de problemas identificados de la urbe y de las PYMES, tomando en cuenta criterios de calidad, eficiencia y competitividad.

\section{NIVEL 8 - Red de Aprendizaje 8: Investigación y gestión de Proyectos de Diseño}

$\mathrm{Al}$ final de esta red el estudiante estará en capacidad de: Estructurar el conocimiento adquirido y aplicarlo en el Trabajo de Integración Curricular, para configurar propuestas viables y novedosas de comunicación visual que puedan evidenciar las competencias profesionales adquiridas en la Carrera. Además, integra a su formación los conocimientos sobre emprender en Diseño, la gestión y evaluación que le permite construir competencias del perfil profesional útiles para la vida laboral.

\section{5b) Problemas que actuarán como ejes de organización de los contenidos.}

En la carrera de Diseño Gráfico se han identificado los siguientes problemas, procesos y situaciones que serán los ejes organizadores de cada unidad.

Unidad Básica: Período Académico I, II y III

En estos períodos académicos se abordarán los problemas del contexto:

P2. Deficiencia en la calidad de propuestas persuasivas visuales en el campo de la publicidad, propaganda, comunicaciones de interés social y revestimiento de envases, para la promoción y comercialización de productos y servicios.

P4. Bajo nivel de soluciones creativas, innovadoras de diseño de mensajes visuales que posibiliten el logro de eficiencia, seguridad, bajo nivel de desgaste físico y optimización de recursos.

Los problemas de comunicación que exigen al Diseño configurar mensajes para informar, persuadir, educar, administrar o identificar se abordan en primera instancia desde los fundamentos. El estudio del signo, el mensaje, la unidad de sentido hasta llegar al discurso permiten comprender la estructura del lenguaje gráfico que junto con el estudio de los elementos del Diseño (forma y espacio, color, tipografía, imagen y composición) acompañan a la comprensión para la estructuración de mensajes gráficos efectivos. Estos elementos permiten definir la organización curricular de la Unidad Básica de primero, segundo y tercer nivel y plantean el eje de integración mediante ejercicios y micro proyectos basados en análisis de casos, experiencias, oportunidades o problemas.

Los problemas de la formación del Diseño que abordará la Unidad de organización básica tienen que ver con la adquisición de las bases teóricas y metodológicas que sustentan y posibilitan la construcción de mensajes gráficos dentro de las distintas áreas de práctica profesional, dichas bases se abordan durante el primero, segundo y tercer nivel mediante: 
- El conocimiento y reflexión sobre la historia del diseño.

- El saber y la aplicación de los fundamentos básicos del Diseño Gráfico en cuanto a los conceptos de forma, espacio, tipografía y color.

- La profundización en la estructuración de mensajes visuales partiendo desde el signo, luego el mensaje hasta la unidad de sentido.

- Desarrollo del pensamiento lógico matemático aplicado directamente al Diseño Gráfico.

- Comprensión de los principios de escritura académica y expresión oral.

- El conocimiento de las TICs y tecnologías aplicadas al Diseño Gráfico, y las herramientas y habilidades de representación gráfica y composición fotográfica de los proyectos de Diseño.

- El acercamiento a la realidad intercultural de nuestro país.

La pregunta que guía esta unidad es: ¿Cuáles son los elementos que fundamentan y posibilitan la construcción de mensajes gráficos?

Unidad Profesional: Período Académico IV, V, VI, VII y VIII

En estos períodos académicos se abordarán los problemas del contexto:

P1. Deficiencia en el diseño de piezas editoriales y material didáctico; señalización y familiarización con interfaces para medios digitales, impresos, tridimensionales o electrónicos. P3. Reducida e insuficiente calidad de material educativo para apoyar el desarrollo e inclusión tanto de individuos como de comunidades que aporten a la valoración de la cultura propia.

P5. Subvaloración de la identidad e imagen organizacional como estrategia de reconocimiento, apropiación y competitividad.

P6. Escaso nivel de propuestas comunicacionales visuales que propicien y concienticen la conservación del patrimonio natural y cultural.

En la unidad profesional se profundiza en las asignaturas y proyectos integradores en cuarto nivel en el diseño de información que enfrenta la mayoría de los problemas del contexto en los aspectos de información especializada, luego el Diseño de identidad gráfica en quinto y el Diseño para nuevos medios en sexto nivel. Estas áreas integran a las demandas específicas de los problemas y también a las necesidades de formación que exigen los contextos laborales en que actúan los graduados. En séptimo nivel se incorpora la visión estratégica para profundizar en el meta proyecto y preparar al estudiante a enfrentar problemas de mayor complejidad e integrar metodologías de investigación y análisis interdisciplinarios para generar conceptos que permitan promover ventajas diferenciales y valor simbólico de marca. El trabajo en equipo es fundamental también en esta etapa y la integración multi, inter y transdisciplinar.

Los problemas, procesos o situaciones de la profesión que se abordan en cuarto y quinto semestre son:

- Comprensión de los conceptos teóricos para configurar mensajes gráficos que tomen en cuenta los medios impresos y digitales para su difusión y la adecuada codificación visual.

- Los conceptos de las teorías de la comunicación y el Diseño Gráfico como discurso social y cultural. 
- Los procesos de aprendizaje centrados en los proyectos de integración de Diseño de Información y Diseño de Identidad de marca permiten configurar soluciones gráficas que consideren los aspectos tecnológicos de la producción gráfica y su representación hasta los contextos sociales y de mercado en donde intervienen.

- Se abordan también problemáticas que permiten reflexionar sobre la ética profesional del Diseño y las reflexiones críticas sobre su quehacer.

La pregunta que guía a estos niveles de la unidad es: ¿Cuáles son los aspectos teóricos, metodológicos, tecnológicos, del contexto social y éticos que definen la construcción de mensajes gráficos?

En el núcleo problemático de sexto y séptimo semestre y que se encuentra dentro de la unidad de organización profesional se aborda:

- Las situaciones de la profesión que permite comprender al Diseño Gráfico desde una visión en la construcción de experiencias integradas, nuevos medios de comunicación y con visión estratégica para entornos competitivos.

- El quehacer proyectual desde los proyectos integradores permite abordar los proyectos de Diseño desde las demandas comunicativas de conversación, participación, interacción, activismo responsable y crítica.

- Estos aspectos se integran desde una visión de Diseño de Comunicación propuesta en el horizonte epistemológico.

- Se profundiza también dentro de los proyectos integradores sobre el diseño con función estratégica en donde el design thinking o pensamiento de Diseño propone la construcción de estrategias competitivas orientadas desde una visión del meta proyecto (contexto) para luego configurar los elementos de Diseño impresos y digitales que materialicen de forma coherente la estrategia de la organización.

- Se profundiza en la visión de marketing para cimentar la transición del agregar valor al producto y servicio a la construcción de marcas que convoquen experiencias significativas.

- Desde este planteamiento se propone el fortalecer la ventaja competitiva y el cumplimiento exitoso de los objetivos organizacionales.

- Al integrarse en esta etapa las prácticas laborales es necesario completar el estudio sobre la viabilidad económica y técnico productiva necesaria para la configuración de los mensajes gráficos con alta calidad y que orienten mejor el futuro laboral.

La pregunta que guía a estos niveles de la unidad es: ¿Cuáles son los aspectos competitivos, comunicacionales, estratégicos, económicos y del mercado que posibilitan la viabilidad de los mensajes gráficos en las interrelaciones del Diseño y los nuevos contextos?

Unidad de Integración Curricular: Período Académico VIII

En esto período académico se abordarán todos los problemas del contexto y de acuerdo con el área de selección que realice el o la estudiante en su trabajo de Integración Curricular.

En esta unidad se integran también y en muchos casos se abordan los problemas del contexto orientados al Diseño para educación y administración que exigen al estudiante 
incorporar conocimientos interdisciplinarios específicos de las áreas de psicología, pedagogía, didáctica, administración, gestión y comunicación organizacional, comunicación interna, comunicación estratégica, etc. que enriquecen los proyectos, sus competencias y definen su perfil de formación con mayor especificidad. En los proyectos de titulación se abordan también las áreas de Identidad de marca, Diseño de persuasión y el Diseño de información junto con el Diseño de nuevos medios que están presentes permanentemente Los problemas, procesos o situaciones de la disciplina que se abordan en esta etapa tienen como cometido:

- Consolidar las competencias adquiridas a lo largo de la carrera y que posibiliten enfrentar problemas de comunicación gráfica desde una óptica adecuada y de práctica profesional bien definida.

- Se reflexiona sobre los aspectos de la metodología de la investigación en Diseño para la definición adecuada de los problemas u oportunidades detectadas o las necesidades planteadas por comitentes definidos.

- Se revisa y fortalece el proceso proyectual y el desarrollo pertinente del proceso de ideación y conceptualización.

- Se profundiza en la construcción de marcos teóricos pertinentes que permitan fundamentar los proyectos desde las distintas necesidades de informar, persuadir, educar, administrar o identificar. Las teorías que permiten construir la base de los proyectos generalmente son transdisciplinares por la naturaleza del Diseño.

- Se revisa los aspectos técnicos de la configuración de mensajes y su producción gráfica. Todo el proceso se realiza integrando la validación teórica, metodológica del Diseño y las demandas del comitente y públicos destinatarios.

- Para la presentación del trabajo se aborda los aspectos esenciales del trabajo académico como la redacción y el uso de normas.

- Se integra a esta etapa reflexiones y prácticas sobre la gestión, planteamiento y diseño de proyectos y emprendimientos creativos.

La pregunta que guía esta unidad es: ¿Cuál es la estructura académica del proyecto de Diseño de grado y su viabilidad, así como las exigencias de la práctica profesional?

\section{5c) Perfil de egreso (resultados de aprendizaje)}

Los resultados de aprendizaje propuestos dentro del modelo de competencias se orientan en cuatro áreas saber hacer, saber saber, saber ser y saberes genéricos. El logro de estos resultados conformará el perfil de egreso de los estudiantes al finalizar el plan de estudio y orienta al mezo y micro currículo en su implementación. Esta propuesta se desarrolló integrando las propuestas del currículo anterior de la carrera, las competencias propuestas por (ICOGRADA, n.d.) y las de la PUCE a nivel de competencias generales. 


\section{Saber ser}

- Demostrar compromiso y sensibilidad frente a las necesidades que plantean la realidad social y el medioambiente desde una visión cimentada en el humanismo, los valores cristianos y un enfoque multi, inter y transdisciplinar y en la toma de decisiones frente al proyecto de Diseño.

- Trabajar en un entorno global con la comprensión de la importancia de la conservación y promoción del patrimonio cultural generando propuestas gráficas con conceptos propios y expresiones genuinas enmarcados en la ética personal y profesional.

- Comprender ampliamente los problemas relacionados con los contextos cognitivos, sociales, culturales, tecnológicos y económicos para el diseño por medio de la investigación cercana a los públicos y sus necesidades.

- Propiciar consensos, aplicando la inclusión, la empatía, la compasión, la persuasión, la paciencia y el pensamiento crítico. Tener capacidad de ser flexible, ágil y dinámico en la práctica profesional.

- Gestionar y colaborar de forma productiva en grandes equipos interdisciplinarios enfocándose en el objetivo del proyecto y las demandas del público más que los conocimientos propios.

\section{Saber saber}

- Comprender histórica y críticamente la disciplina para reflexionar sobre el impacto que tienen los mensajes gráficos en el contexto social, su contribución a la cultura como al desarrollo de las organizaciones o entornos productivos y con sensibilidad y respeto por la dimensión sociocultural y cosmológica que es parte constitutiva del ser humano.

- Relacionar los fundamentos epistemológicos y metodológicos del proceso de Diseño para la resolución de problemas de comunicación mediante la identificación del problema, la investigación, el análisis, la conceptualización, generación de propuestas, prototipos, pruebas de usuario y la evaluación de resultados en función del desarrollo efectivo de las soluciones de Diseño.

- Identificar los deseos, demandas y necesidades de los públicos destinatarios y del comitente mediante la comprensión de los factores humanos físicos, cognitivos, culturales y sociales que permitan tomar decisiones sobre la forma de los mensajes gráficos.

- Reconocer cómo se comportan los materiales y procesos que contribuyen a la sostenibilidad de los productos para su optimización, viabilizando sus costos y determinando la menor huella ecológica posible, así como las estrategias y prácticas para poder determinar los aspectos contractuales, de presupuestos y de gestión de un proyecto de Diseño Gráfico. - Construir argumentos verbales para las soluciones de Diseño Gráfico que abordan diversos usuarios, audiencias; vida útil y los objetivos comerciales y operativos de las organizaciones.

\section{Saber hacer}

- Aplicar los conocimientos de investigación cualitativa en el diagnóstico de las demandas del comitente y necesidades del público destinatario con el mayor grado de pertinencia, coherencia y consistencia. 
- Diseñar mensajes gráficos efectivos y con alto valor simbólico, considerando los requerimientos del comitente, del público destinatario y las especificaciones técnicas y que den respuesta a problemas de comunicación, incluyendo la comprensión de la jerarquía, la tipografía, la estética, composición y construcción de imágenes significativas y el uso de fundamentos y elementos básicos del Diseño Gráfico.

- Representar los mensajes gráficos y sus especificaciones constructivas por medios informáticos y tecnológicos empleando planos técnicos y documentación que contemple las normativas correspondientes y procurando su viabilidad productiva y económica, así como la eficiencia individual y de la organización en caso de que su trabajo sea en relación laboral.

- Aplicar las teorías de la comunicación, lingüística, semiología, retórica, psicología, entre otras, en la resolución de problemas de comunicación gráfica y en donde se evidencie la pertinencia en la codificación del lenguaje gráfico y su efectividad en la construcción de unidades de sentido novedosas y que aporten a enriquecer la cultura material del país. - Gestionar tareas, proyectos y programas para ofrecer los resultados previstos, dentro del presupuesto, el calendario u otras limitaciones definidas, mediante criterios de evaluación permanente que den cuenta de la audiencia y el contexto en donde se implementa el proyecto y que respeten la propiedad intelectual del diseñador como productor de mensajes gráficos y de las instituciones u organizaciones asociadas.

\section{Saberes generales}

Los resultados de aprendizaje relacionados a las capacidades cognitivas y competencias genéricas que son necesarios para el futuro ejercicio profesional de Diseño Gráfico se enmarcan en la propuesta de la PUCE y se consolidan en las asignaturas comunes definidas institucionalmente, Los resultados son:

- Manejar el lenguaje oral y escrito para comunicarse con pertinencia e idoneidad en los diferentes contextos académicos, científicos, laborales y profesionales, así como en otros ámbitos socioculturales, empleando códigos y registros lingüísticos adecuados a las necesidades comunicativas que se presentan.

- Aplicar las TIC para optimizar sus comunicaciones, aprendizajes y el desarrollo del conocimiento, en el marco de los desafíos de la sociedad de la información y comunicación, considerando la responsabilidad social que dicho uso comporta para el desarrollo local y global.

- Utilizar el pensamiento lógico y divergente para comprender a los sujetos y proponer alternativas de intervención ante los fenómenos comunicativos.

- Trabajar en equipo, de forma colaborativa y en redes con miras a la creación de ambientes de aprendizaje abiertos, democráticos e interculturales que estimulen la creatividad y el aprendizaje.

- Asumir la formación a lo largo de la vida como base para el alcance de sus metas y realización personal, reflexionando de manera asertiva sobre sus experiencias y buscando la construcción permanente del saber. 


\section{Modelo de investigación}

6a) Objetivos, logros de aprendizaje y metodologías para la formación en investigación en las unidades de organización curricular

Unidad de organización curricular básica.

Objetivos:

- Construir hábitos de investigación a través de la lectura, escritura y empleo de técnicas de estudio adecuadas.

- Contribuir al desarrollo de competencias de formación académica para la comprensión de los elementos que fundamentan y posibilitan la construcción de mensajes gráficos.

Logros de aprendizaje:

- Identifica problemas de fundamentación en la construcción de mensajes gráficos.

- Realiza diagnósticos situacionales de la disciplina.

\section{Metodología de la Investigación:}

- Observación directa y exploratoria.

- Análisis y descripción.

- Investigación bibliográfica.

- Investigación de campo.

- Método de prueba y error.

\section{Unidad de organización curricular profesional.}

\section{Objetivos:}

- Suscitar procesos de investigación que posibiliten la reflexión de los aspectos históricos, teóricos, tecnológicos, del contexto social y del mercado y éticos que definen la construcción de mensajes gráficos dentro del campo de acción de los estudiantes.

- Fortalecer procesos de investigación que promuevan la comprensión de los aspectos competitivos, estratégicos y económicos que permitan la viabilidad de los mensajes gráficos en las interrelaciones del Diseño y los nuevos contextos.

\section{Logros de aprendizaje:}

- Identifica las diferentes problemáticas locales y nacionales del contexto relacionado con el Diseño Gráfico.

- Genera propuestas de solución hipotéticas para dar respuesta a las problemáticas identificadas.

- Coteja las diferentes propuestas de solución en términos de Diseño basado en el análisis de requerimientos del problema.

\section{Metodología de la Investigación:}

- Observación directa y exploratoria.

- Identificación de tendencias y previsiones de futuro

- Análisis de registros de datos 
- Visualización de datos

- Sondeos y comparaciones culturales

- Análisis de la competencia

- Interpretación y análisis de datos.

- Procesamiento de la información.

- Aprendizaje basado en problemas

- Métodos. Inductivo, deductivo.

- Método proyectual.

\section{Unidad de organización curricular de integración Objetivo:}

- Consolidar las competencias de investigación proyectual en el análisis y diagnóstico, propuesta conceptual y desarrollo y validación de la solución en la elaboración del proyecto de titulación desde una perspectiva de calidad, ética y gestión.

\section{Logros de aprendizaje:}

- Establece la metodología de la investigación idónea para la elaboración de su proyecto.

- Propone soluciones viables a los diferentes problemas del contexto relacionados con la disciplina.

- Valida proyectos para solucionar problemáticas en términos de Diseño.

- Concluye el proyecto de grado con una estructura académica adecuada y mediante su evaluación, exposición y defensa.

\section{Metodología de la Investigación:}

- Observación directa y exploratoria.

- Identificación de tendencias y previsiones de futuro

- Análisis de registros de datos

- Visualización de datos

- Sondeos y comparaciones culturales

- Análisis de la competencia

- Procesamiento, análisis y síntesis de información

- Investigación de campo y bibliográfica.

- Estudio de casos.

- Método proyectual.

\section{Prácticas pre profesionales.}

\section{Integración curricular, objetivos y escenarios}

Las prácticas en el currículo de Diseño Gráfico de la PUCE inician en el cuarto nivel dentro de la Unidad Profesional. 
Nivel 4 y 5: Práctica de servicio a la comunidad: 120 horas ( 80 en cuarto y 40 en quinto) En este nivel se realiza la práctica de servicio a la comunidad. En estas prácticas los estudiantes emplean sus competencias logradas hasta este nivel y el docente responsable tiene un rol de acompañante en el proceso. Se considera que en estos niveles el estudiante está en proceso de formación de los valores y actitudes necesarios para enfrentar las prácticas y estas consolidan y aportan a la formación en lo humanístico como eje importante en el modelo de la PUCE.

Objetivo: Desarrollar propuestas de comunicación gráfica efectivas y viables como respuesta a problemas y necesidades de distintos sectores sociales que tengan prioridad.

Orientación: La práctica se orienta a que el estudiante se involucre de forma guiada con el contexto en donde se demandan soluciones de Diseño Gráfico haciendo uso de sus competencias adquiridas y proponga acciones eficientes y viables dentro del programa de acción social de la PUCE. El docente tutor de la práctica cumplirá funciones de acompañante.

Escenario: proyectos de servicio comunitario, en escenarios externos a la Universidad, tales como asentamientos humanos en sectores rurales o urbanos marginales, con la participación de empresas e instituciones públicas, privadas y comunitarias. Esta práctica se encuentra dentro de las líneas de los proyectos de vínculo de la PUCE.

\section{Nivel 6: Práctica laboral: 120 horas}

En estas prácticas los estudiantes emplean autónomamente sus competencias profesionales y el docente responsable tiene un rol de acompañamiento. Se considera que en estos niveles el estudiante ha logrado también los valores y actitudes necesarios para enfrentar las prácticas. El estudiante en esta práctica deberá integrar los conocimientos del eje de Taller de Diseño de la Unidad Profesional en las áreas de Diseño de información, identidad gráfica y nuevos medios específicamente.

Objetivo: Desarrollar propuestas de comunicación gráfica efectivas y viables como respuesta a problemas y necesidades de distintos espacios académicos, sociales o públicos.

Orientación: La práctica se orienta a que el estudiante se involucre de forma autónoma con el contexto en donde se demandan soluciones de Diseño Gráfico haciendo uso de sus competencias adquiridas y con sensibilidad proponga acciones eficientes y viables El docente tutor de la práctica cumplirá funciones de acompañamiento.

\section{Nivel 7: Práctica laboral: 120 horas}

En este nivel se realiza la práctica en entornos productivos. En estas prácticas los estudiantes emplean autónomamente sus competencias profesionales y el docente responsable solo tiene un rol de monitor. Se considera que en estos niveles el estudiante ha logrado también los valores y actitudes necesarios para enfrentar las prácticas. El estudiante en esta práctica deberá integrar los conocimientos del eje de Taller de Diseño de la Unidad Profesional en las áreas de Diseño de información, identidad gráfica, nuevos medios y Diseño estratégico. Esta práctica al ser la última prepara también al estudiante para su vinculación laboral en el medio externo. Objetivo: Integrar los conocimientos teóricos y prácticos en la solución de problemas reales que demanden un enfoque de comunicación y estrategia en la construcción de mensajes gráficos. 
Orientación: Esta práctica se orienta a que el estudiante se involucre, investigue y aplique sus competencias de formación a problemas o necesidades de un comitente real en los sectores público, privado o social.

En esta práctica el estudiante podrá cumplir también el rol de asistente de cátedra o de investigación en asignaturas o proyectos que demanden y justifiquen esta necesidad. El docente responsable de la práctica cumplirá funciones de monitor.

Escenarios: Micro, pequeñas y medianas empresas (MiPyMes) que constituirán entornos de simulación y permitirán prácticas de campo, modelización, resolución de problemas de diseño gráfico y producción técnica en el ámbito del diseño con orientación al diseño de comunicación y diseño estratégico explicados en los horizontes epistemológicos.

\section{Competencias que se fortalecen con la formación práctica del futuro profesional}

Las habilidades, competencias y desempeños profesionales del Diseño Gráfico que se fortalecen con las prácticas pre profesionales son:

- Demostrar compromiso y sensibilidad frente a las necesidades que plantean la realidad social y el medioambiente desde una visión cimentada en el humanismo, los valores cristianos y un enfoque inter, tras y multidisciplinar y en la toma de decisiones frente al proyecto de Diseño.

- Trabajar en un entorno global con la comprensión de la importancia de la conservación y promoción del patrimonio cultural generando propuestas gráficas con conceptos propios y expresiones genuinas enmarcados en la ética personal y profesional.

- Comprender ampliamente los problemas relacionados con los contextos cognitivos, sociales, culturales, tecnológicos y económicos para el diseño por medio de la investigación cercana a los públicos y sus necesidades.

- Propiciar consensos, aplicando la inclusión, la empatía, la compasión, la persuasión, la paciencia y el pensamiento crítico. Tener capacidad de ser flexible, ágil y dinámico en la práctica profesional.

- Gestionar y colaborar de forma productiva en grandes equipos interdisciplinarios enfocándose en el objetivo del proyecto y las demandas del público más que los conocimientos propios.

- Comprender histórica y críticamente la disciplina para reflexionar sobre el impacto que tienen los mensajes gráficos en el contexto social, su contribución a la cultura como al desarrollo de las organizaciones o entornos productivos y con sensibilidad y respeto por la dimensión sociocultural y cosmológica que es parte constitutiva del ser humano.

- Relacionar los fundamentos epistemológicos y metodológicos del proceso de Diseño para la resolución de problemas de comunicación mediante la identificación del problema, la investigación, el análisis, la conceptualización, generación de propuestas, prototipos, pruebas de usuario y la evaluación de resultados en función del desarrollo efectivo de las soluciones de Diseño.

- Identificar los deseos, demandas y necesidades de los públicos destinatarios y del comitente mediante la comprensión de los factores humanos físicos, cognitivos, culturales y sociales que permitan tomar decisiones sobre la forma de los mensajes gráficos. 
- Reconocer cómo se comportan los materiales y procesos que contribuyen a la sostenibilidad de los productos para su optimización, viabilizando sus costos y determinando la menor huella ecológica posible, así como las estrategias y prácticas para poder determinar los aspectos contractuales, de presupuestos y de gestión de un proyecto de Diseño Gráfico. - Construir argumentos verbales para las soluciones de Diseño Gráfico que abordan diversos usuarios, audiencias; vida útil y los objetivos comerciales y operativos de las organizaciones.

- Aplicar los conocimientos de investigación cualitativa en el diagnóstico de las demandas del comitente y necesidades del público destinatario con el mayor grado de pertinencia, coherencia y consistencia.

- Diseñar mensajes gráficos efectivos y con alto valor simbólico, considerando los requerimientos del comitente, del público destinatario y las especificaciones técnicas y que den respuesta a problemas de comunicación, incluyendo la comprensión de la jerarquía, la tipografía, la estética, composición y construcción de imágenes significativas y el uso de fundamentos y elementos básicos del Diseño Gráfico.

- Representar los mensajes gráficos y sus especificaciones constructivas por medios informáticos y tecnológicos empleando planos técnicos y documentación que contemple las normativas correspondientes y procurando su viabilidad productiva y económica, así como la eficiencia individual y de la organización en caso de que su trabajo sea en relación laboral.

- Aplicar las teorías de la comunicación, lingüística, semiología, retórica, psicología, entre otras, en la resolución de problemas de comunicación gráfica y en donde se evidencie la pertinencia en la codificación del lenguaje gráfico y su efectividad en la construcción de unidades de sentido novedosas y que aporten a enriquecer la cultura material del país. - Gestionar tareas, proyectos y programas para ofrecer los resultados previstos, dentro del presupuesto, el calendario u otras limitaciones definidas, mediante criterios de evaluación permanente que den cuenta de la audiencia y el contexto en donde se implementa el proyecto y que respeten la propiedad intelectual del diseñador como productor de mensajes gráficos y de las instituciones u organizaciones asociadas.

Con las prácticas preprofesionales se fortalecen y consolidan las competencias generales determinadas en el perfil de egreso que son:

- Comprensión holística, estratégica e histórico crítico del contexto y la profesión que le permita situar las problemáticas o necesidades y dar respuestas efectivas desde una visión teórica y conceptual adecuada.

- Efectividad en el planteamiento de soluciones de Diseño de comunicación que se orienten a la experiencia de los usuarios como al desarrollo de ventajas competitivas para organizaciones y entornos productivos desde el pensamiento de Diseño.

- Capacidad intuitiva y creativa para la ideación, representación y producción de propuestas conceptuales innovadoras, así como capacidad lógica de análisis y síntesis de la información para orientar las soluciones de forma efectiva. 
- Dominio de tecnologías digitales y tradiciones para la ideación, representación y producción eficiente tomando en cuenta la calidad de los proyectos en el uso de materiales, procesos y costos con criterios de impacto ecológico.

- Destrezas de investigación para el desarrollo de soluciones y como base para el aprendizaje continuo, los nuevos planteamientos, el desarrollo de nuevas tecnologías o aplicaciones innovadores de tecnologías existentes y nuevas iniciativas.

- Capacidad de gestión, emprendimiento e innovación apuntando a la excelencia y por medio de una actitud responsable, ética, honesta y con integridad.

- Actitud de escucha, apertura y diálogo para la construcción de relaciones cordiales, respetuosas e interculturales, en procura del desarrollo personal y colectivo.

\section{Ambientes de aprendizaje.}

Los ambientes y procesos que permiten implementar el aprendizaje están académicamente estructurados por medio del desarrollo de ejercicios y proyectos de Diseño Gráfico desde la comprensión de los fundamentos hasta su desarrollo en base a un proceso de investigación e implementación riguroso. En la Unidad Básica las asignaturas de Diseño y Comunicación Gráfica permiten la integración de saberes y la comprensión y aplicación práctica de los fundamentos de los proyectos. En la Unidad Profesional las asignaturas de Taller de Diseño permiten la construcción de ambientes en donde se forma las competencias orientadas a las áreas de práctica profesional que son el diseño para información, persuasión, educación, administración y se profundiza en diseño de identidad de marcas, de nuevos medios y diseño estratégico. Finalmente, en la Unidad de Integración Curricular mediante la asignatura de proyecto de titulación se estructura el trabajo de graduación en relación con la solución de problemas de Comunicación Visual y específicamente de Diseño Gráfico considerando las realidades del contexto social y empresarial y la coyuntura nacional.

En las asignaturas descritas se realizarán procesos de investigación, ideación, así como modelos físicos y virtuales, representaciones gráficas, ejercicios exploratorios, y análisis referenciales. Con el apoyo de diversas herramientas y equipo técnico que se imparte en otras asignaturas prácticas y de formación tecnológica como son el Taller de Fotografía, las asignaturas de Tecnología aplicada al Diseño Gráfico, Representación Gráfica, Producción Gráfica y Producción Audiovisual se consolida este aprendizaje práctico.

De igual forma las asignaturas que permiten generar competencias prácticas sobre el proyecto de Diseño son articuladoras de procesos para:

- Desarrollo de ejercicios y proyectos de integración de aprendizajes en las asignaturas integradoras en los niveles I al VII

- Desarrollo del Proyecto de titulación en el nivel VIII

Los ambientes descritos anteriormente son complementados permanentemente con las actividades y procesos que se planifican en: 
- Programa de Vinculación con la Sociedad

- Programa de prácticas laborales curriculares y monitoreadas.

- Programas de voluntariado del Departamento de Pastoral de la PUCE

- Sistema de Tutorías de la Carrera.

- Asistencias de cátedra dentro del proceso de práctica pre profesional.

- Prácticas dentro de proyectos de investigación de la PUCE

- Salidas de campo dentro y fuera de la ciudad, nacionales e internacionales.

- Estudios de caso in situ dentro de las asignaturas.

- Visitas académicas guiadas a empresas y PyMES del sector productivo gráfico.

- Conferencias y seminarios.

- Intercambios académicos internacionales.

- Talleres intensivos (“workshops") con profesionales del medio, profesores nacionales de otras universidades, y profesionales y profesores internacionales.

- Exposiciones, muestras de evaluación y confrontación de los proyectos de Diseño Gráfico.

- Participación en concursos de Diseño Gráfico nacionales e internacionales.

- Cursos y seminarios especializados, curriculares y extracurriculares, dentro y fuera del país.

- Preparación y evaluación para el Examen de competencias específicas de la Carrera.

Entre los ambientes tecnológicos y virtuales para el aprendizaje, la PUCE cuenta con la Dirección de Informática encargada de coordinar las aulas con equipos informáticos y software especializado para Diseño Gráfico contempladas como instrumento de trabajo base para todas las materias integrantes de los campos de formación del currículo: Fundamentos teóricos, Praxis profesional, Epistemología y metodología de la investigación, Integración de saberes, contextos y culturas, y Comunicación y Lenguaje.

De igual manera la principal plataforma habilitada en todos los espacios educativos, sin ser la única, es Moodle. Todas las aulas cuentan con servicios multimedia, que incluyen computadores, proyectores multimedia, conexión a internet, pantallas de proyección, etc. La Oficina de Nuevas Tecnologías de la PUCE administra las plataformas informáticas para el manejo del aprendizaje y ofrece capacitación a los docentes para crear aulas virtuales. Este espacio virtual cuenta con:

- Aulas virtuales de PUCEMoodle.

- Clases virtuales, audio y videoconferencias, reuniones colaborativas, Webinars (seminarios en línea), grabaciones, etc. utilizando la plataforma Blackboard Collaborate.

- Acceso a cursos en línea mediante Massive Open Online Courses (MOOC), esto es cursos masivos en línea y accesibles al público en general.

- Salas de audio y video conferencia.

- Particularmente, en los campos de formación de currículo se dispone de acceso a 7 Bibliotecas Virtuales: EBL, EBSCO, Ebooks, Springer, GetAbstract, Digitalia, Ebrary, E-Libro. 


\section{Notas:}

1. Modelo pedagógico propuesto por la Compañía de Jesús y que es ampliamente conocida y empleada en las instituciones regentadas por la compañía y propuesta en base a los ejercicios espirituales de su principal el Sacerdote San Ignacio de Loyola S.J.

2. Según Granados, se traduce como "interiorizar"

3. https://foroalfa.org/articulos/que-es-como-piensa-y-que-hace-un-disenador-estratega

\section{Bibliografía}

CES, C. de E. S. del E. Reglamento de Régimen Académico (2019).

CNP, C. N. de P. Plan Nacional de Desarrollo 2017-2021 Toda una Vida (2017). Ecuador. Recuperado de: https://www.planificacion.gob.ec/wp-content/uploads/downloads/2017/10/ PNBV-26-OCT-FINAL_0K.compressed1.pdf

CONEA, C. N. de E. y A. de la E. S. del. (2009). EVALUACIÓN DE DESEMPEÑO INSTITUCIONAL DE LAS UNIVERSIDADES Y ESCUELAS POLITECNICAS DEL ECUADOR. Quito. Recuperado de: https://www.educacionsuperior.gob.ec/wp-content/uploads/ downloads/2012/07/Extracto_informe_CONEA.pdf

DDC, D. D. C. (2016). Design Ladder. Retrieved from https://danskdesigncenter.dk/en/ design-ladder-four-steps-design-use

Duplá, J. (2000). La pedagogía Ignaciana. Una ayuda importante para nuestro tiempo. In Cuadernos Ignacianos 2. Conferencias sobre pedagogía Ignaciana (p. 189). Caracas: Universidad Católica Andrés Bello. Recuperado de: https://ecommons.luc.edu/cgi/ viewcontent.cgi? article $=1585 \&$ context=ignatianpedagogy

Franky Rodriguez, J. (2015). El Acto de Diseñar....entre otras quijotadas (1era ed.). Quito: Pontificia Universidad Católica del Ecuador, Facultad de Arquitectura Diseño y Artes.

Frascara, J. (2012). El diseño de comunicación (1a ed 3a r). Buenos Aires: Ediciones Infinito. ICOGRADA, I. C. of G. D. A. (n.d.). Icograda Design Education Manifesto 2011. Taipei. Recuperado de: https://www.ico-d.org/database/files/library/IcogradaEducationManifesto_2011.pdf

Larrea de Granados, E. (2015). El currículo de la educación superior desde la complejidad sistémica. Quito. Retrieved from http://www.ces.gob.ec/doc/Taller-difusion/SubidoAbril-2015/curriculo_es-sistemico - e larrea.pdf

Muñoz, J. L. A. (2009). Metodología del Diseño, de la Ciencia y del Espíritu. México D.F. Recuperado de: https://comunifad.files.wordpress.com/2018/01/jorge-luis-muc3b1ozmetodo-disec3b1o-8-2-5-0.docx

PUCE, P. U. C. del E.-C. de D. G. (2019a). Declaración del Ajuste del Rediseño Curricular de la Carrera de Diseño Gráfico PUCE. Quito.

PUCE, P. U. C. del E.-C. de D. G. (2019b). Proyecto de Ajuste del Rediseño Curricular de la Carrera de Diseño Gráfico PUCE. Quito.

Rodríguez Morales, L. (2004). Diseño: estrategia y táctica. México D.F.: Siglo XXI Editores. Sexe, N. (2001). Diseño.com. Buenos Aires: Paidós. 
Yates, D., \& Price, J. (2016). De la Publicidad al Diseño de Comunicación, la revolución creativa que está cambiando el mundo. (1era ed.). Barcelona: Promopress.

\begin{abstract}
With the approval in Ecuador of the new Organic Law of Higher Education (LOES) in 2010 and its respective Academic Regime Regulations (RRA) 2012 and Regulations for the Presentation and Approval of Careers and Programs of Higher Education Institutions (RPACP) ) in 2014 and issued by the Higher Education Council CES, the redesign of undergraduate and postgraduate study programs in the country began. In this context the new proposal of the Graphic Design career is presented, considering the relevance of the curriculum in which the learning of the theoretical knowledge of the discipline of Graphic Design is integrated, with professional skills so that students are able to contribute design solutions from a strategic vision and high symbolic value, oriented to the demands of the public sector, small and medium enterprises, social organizations and communities. A proposal of integral education based on the development of your personal and professional life project based on the strengthening of the vocation, the goal of cognition, self-regulation and personal, social and environmental responsibility, within a framework of observance of ethical values, human and Christian characteristic of Ignatian pedagogy and good living. This proposal framed in the mission and institutional vision of the PUCE is specified in the curriculum that reflects the strengthening of design education based on the resolution of specific problems, with real requirements and users. It takes as its axis the Design project and in its three stages corresponding to the project method. It also relates subjects horizontally and vertically in a unified way, thus converging in the development of short and long projects that demonstrate the competencies that designers must have at their graduation.
\end{abstract}

Keywords: Graphic design - teaching - curriculum - curriculum design.

Resumo: Com a aprovação no Equador da nova Lei Orgânica do Ensino Superior (LOES) em 2010 e seus respectivos Regulamentos do Regime Acadêmico (RRA) 2012 e Regulamentos para Apresentação e Aprovação de Carreiras e Programas de Instituições de Ensino Superior (RPACP) ) em 2014 e emitido pelo Conselho de Ensino Superior da CES, o redesenho dos programas de graduação e pósgraduação começou no país. Nesse contexto, é apresentada a nova proposta do curso de Design Gráfico, considerando a relevância do currículo no qual se integra a aprendizagem dos conhecimen-tos teóricos da disciplina de Design Gráfico, com as habilidades profissionais para que os alunos possam contribuir projetar soluções a partir de uma visão estratégica e de alto valor simbólico, orientada para as demandas do setor público, pequenas e médias empresas, organizações sociais e comun-idades. Uma proposta educacional abrangente, baseada no desenvolvimento de seu projeto de vida pessoal e profissional, com base no fortalecimento de sua vocação, 
metacognição, auto-regulação e responsabilidade pessoal, social e ambiental, dentro de uma estrutura de observância de valores éti-cos, características humanas e cristãs da pedagogia inaciana e do bom viver.

Esta proposta, enquadrada na missão e visão institucional da PUCE, está especificada no currículo e em seu plano de estudos que reflete o fortalecimento do ensino de design com base na resolução de problemas específicos, com requisitos e usuários reais. Ele toma o projeto de design como seu eixo e em seus três estágios correspondentes ao método do projeto. Também relaciona os assuntos horizon-tal e verticalmente de maneira unificada, convergindo, dessa forma, no desenvolvimento de projetos curtos e longos que demonstram as competências que os designers devem ter na graduação.

Palavras chave: Design gráfico - ensino - currículo - desenho curricular.

[Las traducciones de los abstracts fueron supervisadas por el autor de cada artículo] 